\title{
Further Development of the Predictive Models for Physical Properties of Pure lonic Liquids: Thermal Conductivity and Heat Capacity
}

Dol:

10.1016/j.jct.2017.10.010

\section{Document Version}

Accepted author manuscript

Link to publication record in Manchester Research Explorer

Citation for published version (APA):

Oster, K., Jacquemin, J., Hardacre, C., Ribeiro, A. P. C., \& .Elsinawi, A. (2017). Further Development of the Predictive Models for Physical Properties of Pure Ionic Liquids: Thermal Conductivity and Heat Capacity. Journal of Chemical Thermodynamics. https://doi.org/10.1016/j.jct.2017.10.010

\section{Published in:}

Journal of Chemical Thermodynamics

\section{Citing this paper}

Please note that where the full-text provided on Manchester Research Explorer is the Author Accepted Manuscript or Proof version this may differ from the final Published version. If citing, it is advised that you check and use the publisher's definitive version.

\section{General rights}

Copyright and moral rights for the publications made accessible in the Research Explorer are retained by the authors and/or other copyright owners and it is a condition of accessing publications that users recognise and abide by the legal requirements associated with these rights.

\section{Takedown policy}

If you believe that this document breaches copyright please refer to the University of Manchester's Takedown Procedures [http://man.ac.uk/04Y6Bo] or contact uml.scholarlycommunications@manchester.ac.uk providing relevant details, so we can investigate your claim.

\section{OPEN ACCESS}




\section{Accepted Manuscript}

Further Development of the Predictive Models for Physical Properties of Pure Ionic Liquids: Thermal Conductivity and Heat Capacity

K. Oster, J. Jacquemin, C. Hardacre, A.P.C. Ribeiro, A. Elsinawi

PII:

S0021-9614(17)30377-4

DOI: https://doi.org/10.1016/j.jct.2017.10.010

Reference: YJCHT 5244

To appear in:

\section{J. Chem. Thermodynamics}

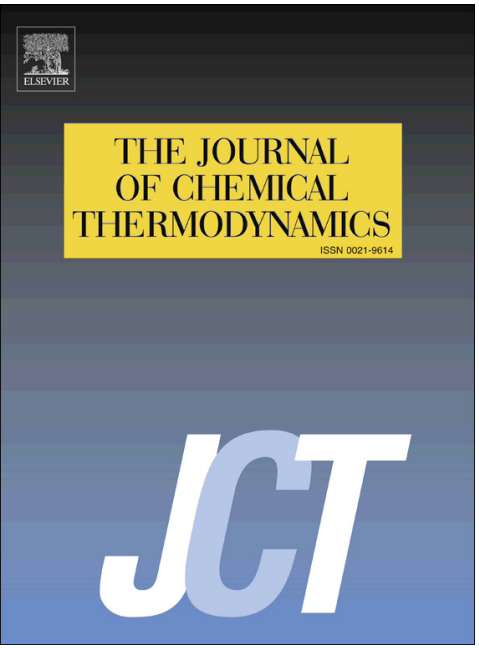

Received Date: $\quad 14$ August 2017

Revised Date: $\quad 5$ October 2017

Accepted Date: $\quad 17$ October 2017

Please cite this article as: K. Oster, J. Jacquemin, C. Hardacre, A.P.C. Ribeiro, A. Elsinawi, Further Development of the Predictive Models for Physical Properties of Pure Ionic Liquids: Thermal Conductivity and Heat Capacity, J. Chem. Thermodynamics (2017), doi: https://doi.org/10.1016/j.jct.2017.10.010

This is a PDF file of an unedited manuscript that has been accepted for publication. As a service to our customers we are providing this early version of the manuscript. The manuscript will undergo copyediting, typesetting, and review of the resulting proof before it is published in its final form. Please note that during the production process errors may be discovered which could affect the content, and all legal disclaimers that apply to the journal pertain. 
Further Development of the Predictive Models for Physical Properties of Pure Ionic Liquids: Thermal Conductivity and Heat Capacity

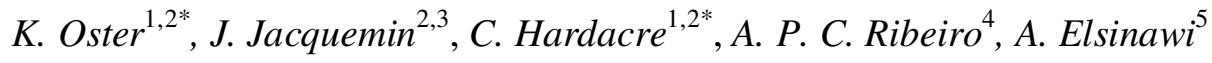

${ }^{1}$ The University of Manchester, School of Chemical Engineering \& Analytical Science, Sackville Street, M13 9PL, Manchester

${ }^{2}$ Queen's University Belfast, School of Chemistry \& Chemical Engineering, Stranmillis Road, BT9 5BW, Belfast

${ }^{3}$ Université François Rabelais, Laboratoire PCM2E, Parc de Grandmont 37200 Tours

${ }^{4}$ Universidade de Lisboa, Centro de Química Estrutural, Instituto Superior Técnico, Av. Rovisco Pais 1, 1049-001, Lisboa

${ }^{5}$ King Fasial University, Materials Engineering Department, College of Engineering, AlHasa, 31982, Hofuf

Efficient, fast and accurate heat transfer units design is currently a 'hot topic' due to the demand for more approachable and high-performance-ability materials. This is usually performed by the prediction of physical properties coupled with sufficient structure searching (for example with genetic algorithm). Ionic liquids have been found to be prospective replacement materials in this case; however, the predictive capabilities of existing models still remain poor which affects their practical application significantly. It has also been observed that for some quaternary-phosphonium based carboxylate ILs, the models fail, particularly, for thermal conductivity and heat capacity predictions. The impact of electronic structure on the heat capacity was confirmed by DFT calculations, and this was also included in further refinement. The aim of this work is to assess the predictive capabilities of existing models for thermal conductivity and heat capacity, with further improvements based on more accurate investigated structure characterization (DFT) and reparameterization (group contribution methodology). The ILs chosen for the initial study are trihexyl(tetradecyl)phosphonium-based carboxylate derivatives. 
Keywords: Ionic Liquids, Physical Properties Prediction, Thermal Conductivity, Heat Capacity, Density Functional Theory. 


\section{Introduction}

Heat transfer fluids (HTFs) are important in the process and energy industries where efficient usage and transfer of energy in the form of heat is critical in the overall process design of the system. There are increasingly high requirements being placed on HTFs which include their price, stability and performance. Ionic liquids (ILs) have been proposed as alternatives to the conventionally HTFs, such as water, ethylene glycol and silicone oil, due to their unique physical properties [1-3]. Briefly, ILs are task specific tunable compounds with unique properties, namely low freezing point, wide liquid range, non-flammability or very low vapor pressure [4], which are strongly dependent on the combination of selected anion and cation that determine, for example, their degree of ionicity and interactions in solution [5-7]. To date, their thermophysical properties have been extensively investigated to assess their real potential in a given process design $[8,9]$. However, to examine the viability of whether IL based-HTFs can be used in a specific application, their thermophysical properties, especially thermal conductivity, heat capacity, density and viscosity, must be accurately determined to allow a better understanding of their structure-properties relationships. In the case of ILs, due to the large number of possible ion combinations and with a goal of reducing the compositional space to be studied experimentally, predictive models have been developed and tested against experimentally determined data [10-25]. Many of these models have been based on those originally applied to molecular solvents using group contribution methods or equation of state relationships [26-30].

Many models, based on group contribution methods, artificial neural networks, or genetic algorithm, have been proposed for the predictions of the ILs thermal conductivity, to date $[10,11,13,15,16,18,20,25,31]$. It is worth noting that the terms 'correlative' and 'predictive' are often wrongly used in a interchangeably manner. The correlative models are thought to be fully based on experimental data (such as viscosity, density or melting point). Meanwhile, the predictive models are usually related to equation-of-state-like methodologies. The third group, evaluative methodologies, are usually assessed with group contribution methods [32]. As well as temperature and compositional effects, a number of studies have included pressure as an input parameter, however, the availability of those data is extremely limited so the errors are potentially large in predicting the $\operatorname{IL}$ properties $[10,15,16,18]$.

The predictive models of heat capacity can be divided into two groups: the Meccano and the Lego approaches. The Meccano approach uses large functional groups (usually whole 
ions) while the Lego approach divides the structure of compounds into smaller functional groups, similar to those in traditional group contribution methods. Most of them are based on group contribution methods [12,14,17,19,23,24,33].

In terms of predictive models, Valderrama's critical parameters for ILs have been used to model their physical properties; however, the critical properties cannot be visualised experimentally as many ILs decompose before their evaporation (boiling point) [21,34,35], which is a major drawback in the validation of the properties. Although they have been applied to predict physiochemical properties of the ILs; moreover, as was shown by Valderrama et al. (2015), deviations for high molecular mass ILs are observed in comparison to simple hydrocarbons and their critical properties [22].

Besides the critical properties and the lack of ability of the current models to introduce the contribution of the molecular mass in the prediction of properties, Wu et al. (2013) found another issue in the $-\mathrm{CH}_{2}-$ group characterization of phosphonium- and ammonium-based ILs in the prediction of thermal conductivity [25]. This was related to different charge environment in these groups of compounds and in comparison to imidazolium-, pyridinium- or pyrrolidinium-based ILs, the group contribution parameters impact differs. Wu et al. (2013) overcame this problem by using three different $-\mathrm{CH}_{2}-$ group parameters in term to type of compound: ammonium, phosphonium or others (imidazolium, pyrrolidinium, pyridinium, etc.) [25].

Based on these above-mentioned observations, the first part of this work is devoted on the truly assessment of the accuracy of existing theoretical models for the evaluation of the thermal conductivity and heat capacity of a range of selected tetraalkyl phosphonium based ILs as a function of temperature. The selected ILs for this study are based on the trihexyl(tetradecyl)phosphonium cation, $\left[\mathrm{P}_{14,6,6,6}\right]^{+}$, and carboxylate anions - acetate, $[\mathrm{AcO}]^{-}$, butanoate, [ButO$]^{-}$, hexanoate, $\left[\mathrm{HexO}^{-} \text {, octanoate, [OctO }\right]^{-}$, and decanoate, $[\mathrm{DecO}]^{-}$, due to their potential for many applications [36-38]. In the light of such analysis, quantum chemical calculations (DFT) were then used to examine the charge distribution of classical ions used to design ILs to drive a more rigorous group contribution parameterisation to further improve the accuracy of such existing models.

The models chosen for the further improvement are $\mathrm{Wu}$ et al. and Ge-Nancarrow in case of thermal conductivity and heat capacity, respectively. The choice was dictated by the 
fact of their simplicity to use and further development which means that the limitations related to them are minimized.

\section{Calculations}

To predict the thermal conductivity $\mathrm{Wu}$ model was used, defined by the following equation [25]:

$$
\lambda(T)=\sum_{i=0}^{2} a_{i}\left(\sum_{j=1}^{k} n_{j} \Delta \lambda_{0, j}\right)^{i}\left[1+k_{0}\left(1-T_{r}\right)^{\frac{2}{3}}\right]
$$

where $a_{i}, \Delta \lambda_{0, j}$ and $k_{0}$ are parameters [25], $n_{j}$ is the number of $j$ group in the molecule, and:

$$
\begin{aligned}
& T_{r}=\frac{T}{T_{c}} \\
& T_{c}=\frac{T_{b}}{0.5703+1.0121 \sum_{j=1}^{k} n_{j} \Delta T_{c}-\left(\sum_{j=1}^{k} n_{j} \Delta T_{c}\right)^{2}} \\
& T_{b}=198.2+\sum_{j=1}^{k} n_{j} \Delta T_{b}
\end{aligned}
$$

where $T_{c}$ is so-called critical temperature and $T_{b}$ is the boiling temperature. In this case, Valerrama's critical and boiling temperature are used; $\Delta T_{b}$ and $\Delta T_{c}$ are the contributions to the boiling and critical temperature, respectively $[21,22,35]$.

The prediction of heat capacity from the model of Ge et al. (2008) [14] and Nancarrow et al. (2015) [17] is done by the following equations:

$$
\begin{aligned}
& C_{p}^{0}(T)=\left(\sum_{i=1}^{k} n_{k} A_{C_{p, i}}-37.93\right)+\left(\sum_{i=1}^{k} n_{k} B_{C_{p, i}}+0.210\right) T+\left(\sum_{i=1}^{k} n_{k} C_{C_{p, i}}-3.91 \times 10^{-4}\right) T^{2} \\
& +\left(\sum_{i=1}^{k} n_{k} D_{C_{p, i}}-2.06 \times 10^{-7}\right) T^{3} \\
& \frac{C_{p}-C_{p}^{0}}{R}=1.586+\frac{0.49}{1-T_{r}}+\omega\left[4.2775+\frac{6.3\left(1-T_{r}\right)^{\frac{1}{3}}}{T_{r}}+\frac{0.4355}{1-T_{r}}\right]
\end{aligned}
$$




$$
\omega=\frac{\left(T_{b}-43\right)\left(T_{c}-43\right)}{\left(T_{c}-T_{b}\right)\left(0.7 T_{c}-43\right)} \log \left[\frac{p_{c}}{0.101325}\right]-\frac{\left(T_{c}-43\right)}{\left(T_{c}-T_{b}\right)} \log \left[\frac{p_{c}}{0.101325}\right]+\log \left[\frac{p_{c}}{0.101325}\right]-1
$$

where $\omega$ is the acentric factor and $A_{C p}, B_{C p}, C_{C p}, D_{C p}$ are the group contribution parameters, $R$ is the gas constant $\left(8.314 \mathrm{~J} \mathrm{~mol}^{-1} \mathrm{~K}^{-1}\right)$, and $p_{c}$ is the critical pressure, in this case Valderrama's critical pressure [14,17]:

$$
p_{c}=\frac{M}{\left(0.2573+\sum_{j=1}^{k} n_{j} \Delta p_{c}\right)^{2}}
$$

The quantum chemical calculations were performed in Gaussian 09W-A02 software. The structure optimization was carried out using ground state density functional theory (DFT) level of theory, B3LYP hybrid functional, DGTZVP basis set [39-41]. In the next step, the Mulliken charge distribution was determined to assess the charge distribution of each selected species $[42,43]$.

To check how reliable the predicted values are, the relative deviation (RD) and average absolute relative deviation (AARD) were calculated as follows:

$$
\begin{aligned}
& R D=\frac{x_{\text {calc }, i}-x_{\text {exp }, i}}{x_{\text {exp }, i}} \times 100 \% \\
& A A R D=\frac{1}{k} \sum_{i=1}^{k}\left|\frac{x_{\text {calc }, i}-x_{\text {exp }, i}}{x_{\text {exp }, i}}\right| \times 100 \%
\end{aligned}
$$

where $k$ is the total number of data points, $x_{c a l c, i}$ and $x_{\text {exp }, i}$ are the calculated and experimental data points (heat capacity or thermal conductivity), respectively.

The group contribution coefficients re-optimization of models was performed in Microsoft Excel using the Solver add-in, and generalized reduced gradient (GRG) nonlinear optimization method (minimization of AARD as set objective up to 10 consistent iterations with central derivatives, constraints precision of $10^{-6}$, and convergence of $10^{-6}$ ).

The structures of all the ILs used for initial access of models are shown in Figure 1. 

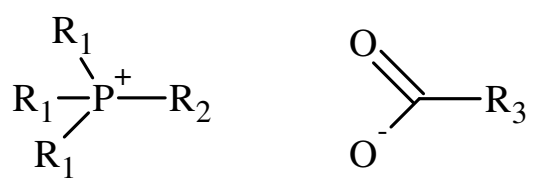

$$
\begin{array}{ll} 
& \mathrm{R}_{1}=-\left(\mathrm{CH}_{2}\right)_{5}-\mathrm{CH}_{3} \\
& \mathrm{R}_{2}=-\left(\mathrm{CH}_{2}\right)_{13}-\mathrm{CH}_{3} \\
{[\mathrm{AcO}]:} & \mathrm{R}_{3}=-\mathrm{CH}_{3} \\
{[\mathrm{ButO}]:} & \mathrm{R}_{3}=\left(\mathrm{CH}_{2}\right)_{2}-\mathrm{CH}_{3} \\
{[\mathrm{HexO}]:} & \mathrm{R}_{3}=\left(\mathrm{CH}_{2}\right)_{4}-\mathrm{CH}_{3} \\
{[\mathrm{OctO}]:} & \mathrm{R}_{3}=\left(\mathrm{CH}_{2}\right)_{6}-\mathrm{CH}_{3} \\
{[\text { DecO }} & \mathrm{R}_{3}=\left(\mathrm{CH}_{2}\right)_{8}-\mathrm{CH}_{3}
\end{array}
$$

Figure 1 Structures of ILs used for initial assessment.

\section{Results}

\section{Quantumchemical calculations}

To fully reflect the group contribution methodology, the exact structure of investigated compounds must be known. In the case of simple organic compounds (i.e. carbohydrates, alcohols, organic acids, etc.), the charge can be successfully neglected as its impact is negligible [44-47], as a result of them acting as van der Waals liquids. However, ILs are known for the many types of interactions occurring between the constituents $[48,49]$. For this reason, the charge distribution is an important factor which must be considered when developing the group contribution methods. Wu et al. (2013) have already included this effect by dividing the parameters in term of cation type [25]. Furthermore, following the works of Benson and Buss (1958) [50], and Joback (1984) [51] in which the group contribution methodology was proposed to be used for heat capacity predictions of molecular solvents, Ge et al. (2008) used this model to predict the heat capacity of ionic liquids [14], Nancarrow et al. (2015) added reoptimized and new groups to the model [17]. As can be noted, none of the model included the charge localization on the molecule, nor the type of cation/anion. It seems to be essential to reconsider this model in order to introduce additional parameters describing the charge distribution on charged species like IL ions.

For this purpose, the calculated Mulliken charges on each atom were used for all selected ions. The comparison of the ILs cations and anions with a van der Waals molecule, hexane, was undertaken due to its entire neutral charge character. It can be seen that hexane can be divided into two regions (Figure 2); the first consists of $-\mathrm{CH}_{3}$ groups with the 
Mulliken charge of $\sim-0.634$ and $\sim 0.206$, for carbon and hydrogen, respectively. The other region consists of $-\mathrm{CH}_{2-}$ groups with the charge of $\sim-0.381$ and $\sim 0.194$, for carbon and hydrogen, respectively.

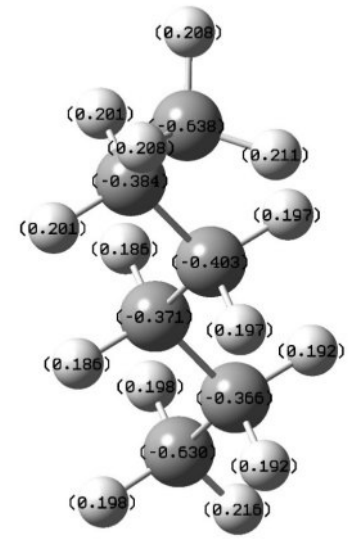

Figure 2 The structure of hexane with calculated Mulliken charges.

The structures of all the considered cations are shown in Figure 3. It can be observed that all nitrogen-based cations (imidazolium, pyridinium, tetraalkyl ammonium, pyrrolidinium and quinolinium) have similar charge distributions with a slightly negative $\mathrm{N}^{+}$ centre with charge of $c a$. -0.090 . This can be explained as charge transfer to groups bonded to the positive N-centre, particularly the first one, which exhibits higher charge than in comparison to other groups. It can be also observed that the following 3 groups from $\mathrm{N}^{+}$ centre are affected, and their behaviour deviated from typically van der Waals-like behaviour, in particular the charge located on hydrogen atoms. It seems reasonable that these should be considered separately from the neutral chains (such as this in hexane). In case of phosphonium cation, the positive charge is located on $\mathrm{P}^{+}$centre, as close to +0.928 , in contrast to N-based. Moreover, the first 3 groups bonded to $\mathrm{P}^{+}$centre are affected, similarly to those of N-based cations. 

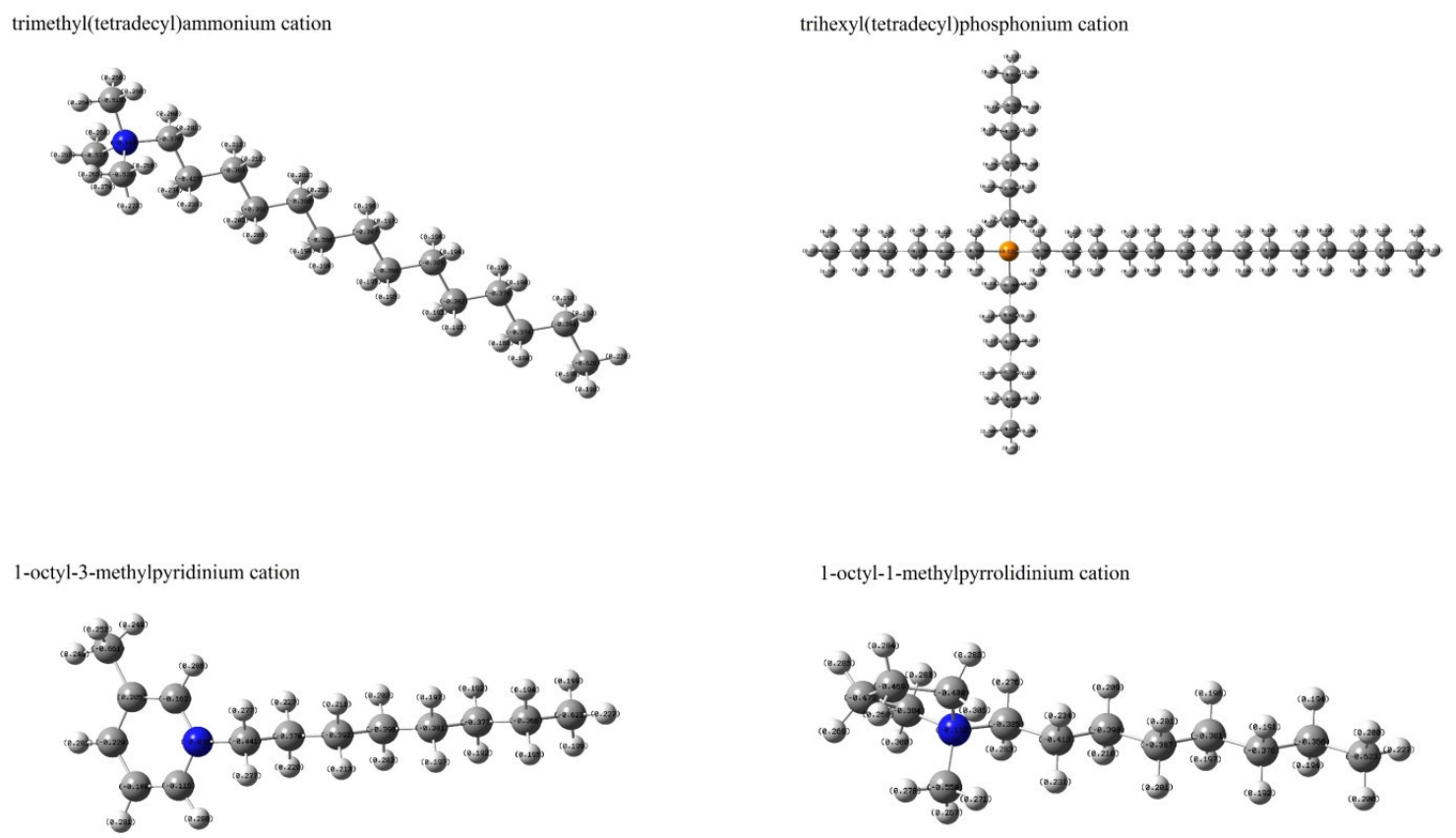

1-octyl-1-methylpyrrolidinium cation
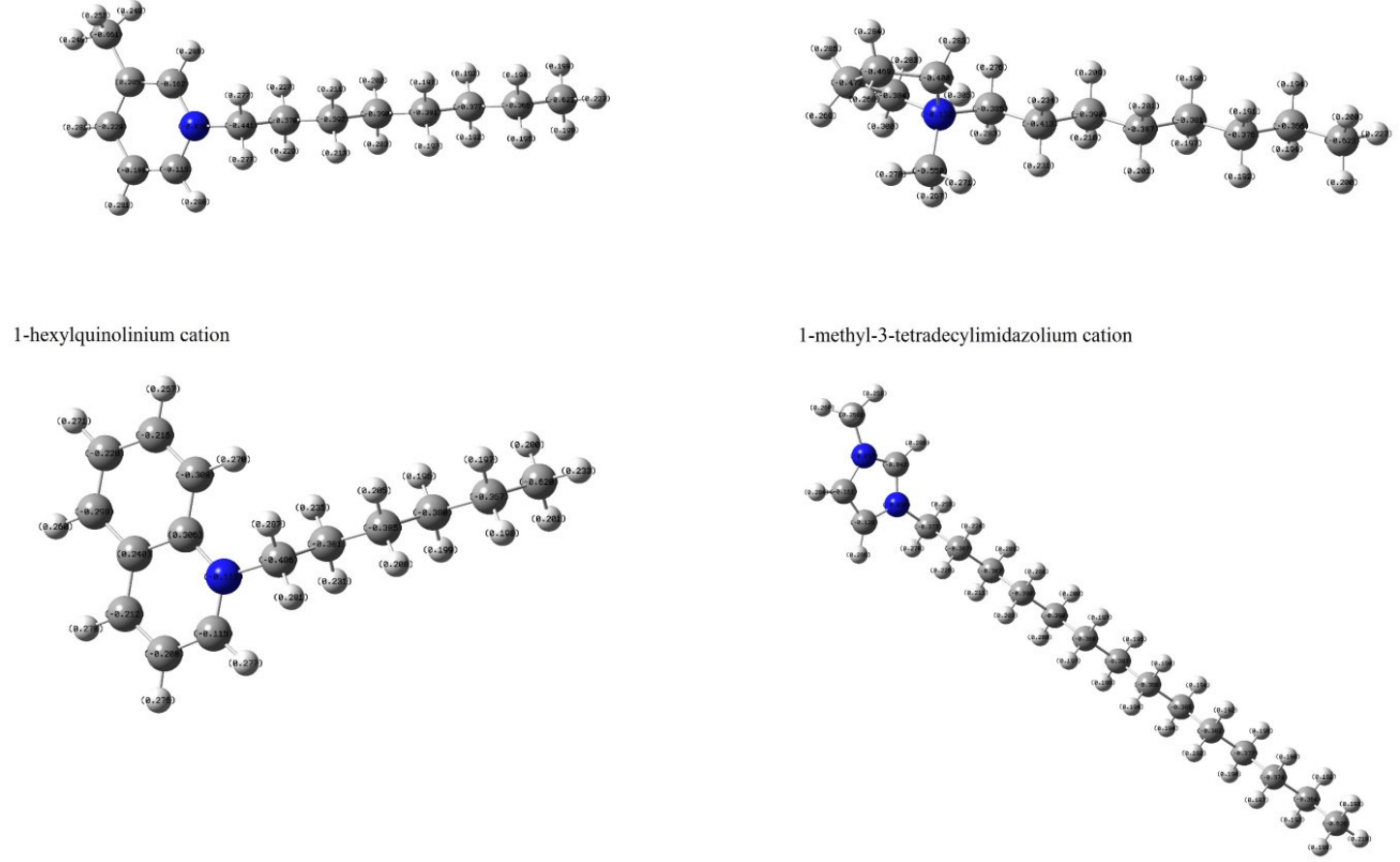

Figure 3 The structures of considered cations with calculated Mulliken charges.

A similar approach was applied to the anions (Figure 4). Moreover, to distinguish the differences between cations and anions that are $\mathrm{N}$ - or P-based, bis[(trifluoromethyl)sulfonyl]imide and hexafluorophosphate anions were considered. It can be seen that the effect of the negative charged group pertains up to the third carbon in the alkyl chain length in the carboxylate anions as found for the cations. Moreover, the nitrogen atom in bis[(trifluoromethyl)sulfonyl]imide anion is highly negative, as expected. It can be 
also observed that the phosphorus atom in hexafluorophosphate anion is highly positive what is caused by the highly electronegative fluorine atoms attached to the central phosphorus.

butanoate anion

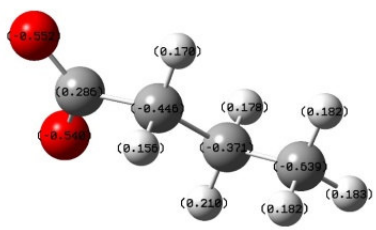

ethylsulfate anion

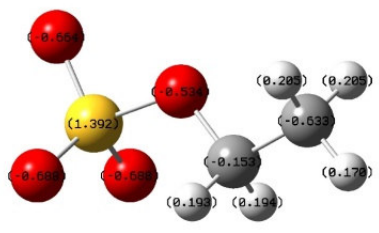

decanoate anion

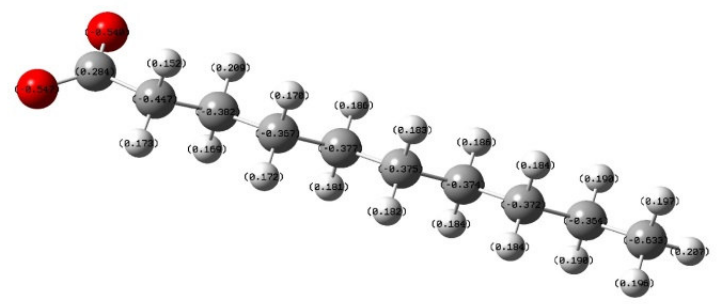

hexafluorophosphate anion

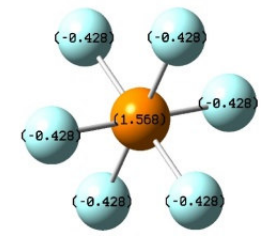

octylsulfate anion

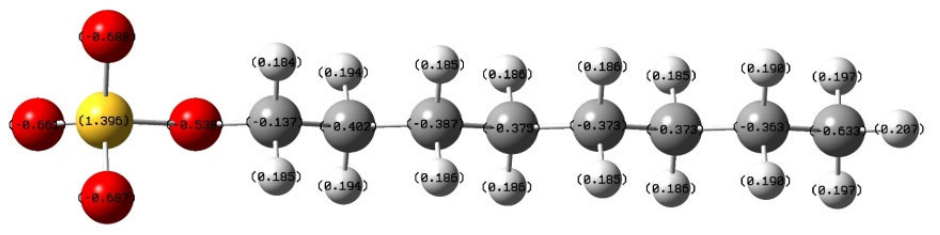

bis[(trifluoromethyl)sulfonyl]imide anion

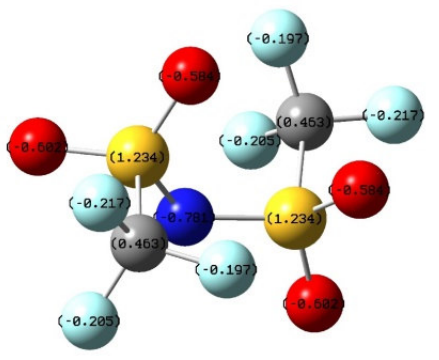

Figure 4 The structures of considered anions with calculated Mulliken charges.

The above considerations allow new groups to be defined which include the charge distribution. These can be characterised as (i) van der Waals-like, N-based, P-based and anion-based $\mathrm{CH}_{3}$ group; (ii) van der Waals-like, N-based, P-based and anion-based $\mathrm{CH}_{2}$ 
group; (iii) neutral, cation-based and anion-based $>\mathrm{N}$ - group; (iv) cation-based and anionbased -P group. The first 3 bound carbon groups to the charged centre (both positively and negatively) are divided in terms of N-based, P-based cations, and anions.
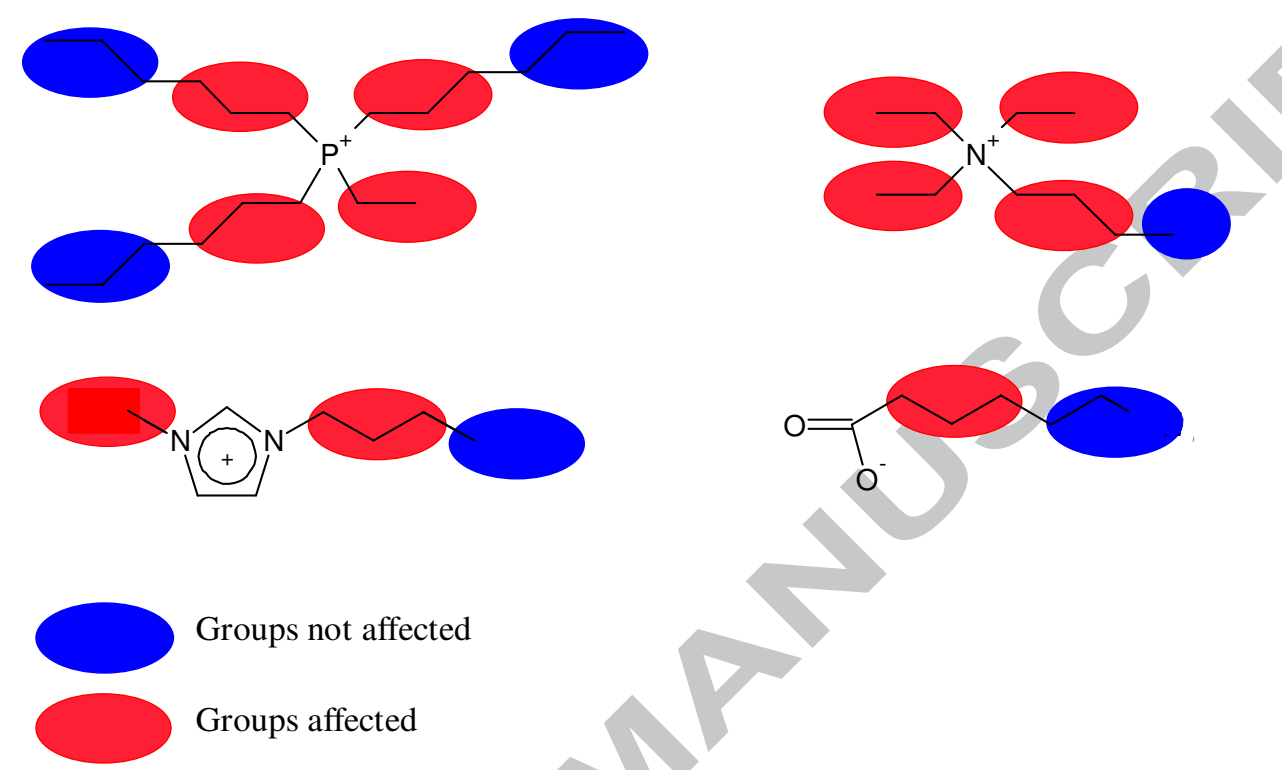

Figure 5 The examples of phosphonium-, ammonium- and imidazolium-based cations, and carboxylate anion, for heat capacity predictions.

Following this approach, the examples can be given (for cations and anion in Figure 5; red are affected by charge, and blue are not affected): (i) for ethyltrihexylphosphonium cation (upper left) $-\left(\right.$ red: $10 \times-\mathrm{CH}_{2}-$-p-based $+1 \times-\mathrm{CH}_{3}$,P-based $)+\left(\right.$ blue: $6 \times-\mathrm{CH}_{2}-$ neutral $+3 \times$ $-\mathrm{CH}_{3}$, neutral); (ii) for butyltrimethylammonium cation (upper right) $-\left(\right.$ red: $6 \times-\mathrm{CH}_{2}-\mathrm{N}$-based + $3 \times-\mathrm{CH}_{3}$-N-based $)+\left(\right.$ blue: $1 \times-\mathrm{CH}_{3}$,neutral); (iii) for 1-butyl-3-methylimidazolium cation (lower left) - (red: $3 \times-\mathrm{CH}_{2}-\mathrm{N}$-based $+1 \times-\mathrm{CH}_{3}-\mathrm{N}$-based $)+\left(\right.$ blue: $1 \times-\mathrm{CH}_{3}-$ neutral); (iv) for heptanoate anion (lower right) - (red: $3 \times-\mathrm{CH}_{2}-$ anion-based $)+\left(2 \times-\mathrm{CH}_{2}-\right.$ neutral $+1 \times-\mathrm{CH}_{3}-$ neutral).

\section{Thermal conductivity}

As an input to test the available models predictive capabilities, a series of trihexyl(tetredacyl)phosphonium acetate $\left[\mathrm{P}_{14,6,6,6}\right][\mathrm{AcO}]$, butanoate $\left[\mathrm{P}_{14,6,6,6}\right][\mathrm{ButO}]$, 
hexanoate $\left[\mathrm{P}_{14,6,6,6}\right][\mathrm{HexO}]$, octanoate $\left[\mathrm{P}_{14,6,6,6}\right][\mathrm{OctO}]$, and decanoate $\left[\mathrm{P}_{14,6,6,6}\right][\mathrm{DecO}]$ ILs were used. This is since this class of ILs (tetraalkylphosphonium cation combined with carboxylate anions) has not been used to establish any of the existing models reported and tested, herein. It has been previously reported that the thermal conductivity coefficient was not dependent on the anion chain length for investigated $\left[\mathrm{P}_{14,6,6,6}\right][R \mathrm{O}] \mathrm{ILs}$, and similar relationships were found for 1-alkyl-3-methylimidazolium-based ILs with different alkyl chain lengths of cation [52]. Regarding the elementary relationship between molar mass of compounds and thermal conductivity [53], the discrepancy which can be found in ILs influences significantly the ability to predict the thermal conductivity coefficient. This error may be the result of strong cation-anion Coulombic interactions [25,42,48]. Moreover, the contribution of hydrogen bonding, as well as van der Waals interactions are not negligible as ILs can form a large variety of these interactions as reported by Hunt et al. (2015) [48]. On the other hand, it was shown in other reports devoted to the predictions that ILs with high molecular mass can deviate from theoretical properties and correction factors are necessary [22].

The predicted values of thermal conductivity for all the ionic liquids studied are summarised in Table S1. Figure 6 shows the experimental data as well as the modelled data as a function of temperature, before and after the optimization. To assess the quality of predictions (in comparison to experimental data), relative deviation (RD) were calculated (Figure 7). Their values were collected in Table S1, and average absolute relative deviation (AARD) in Table 1. 


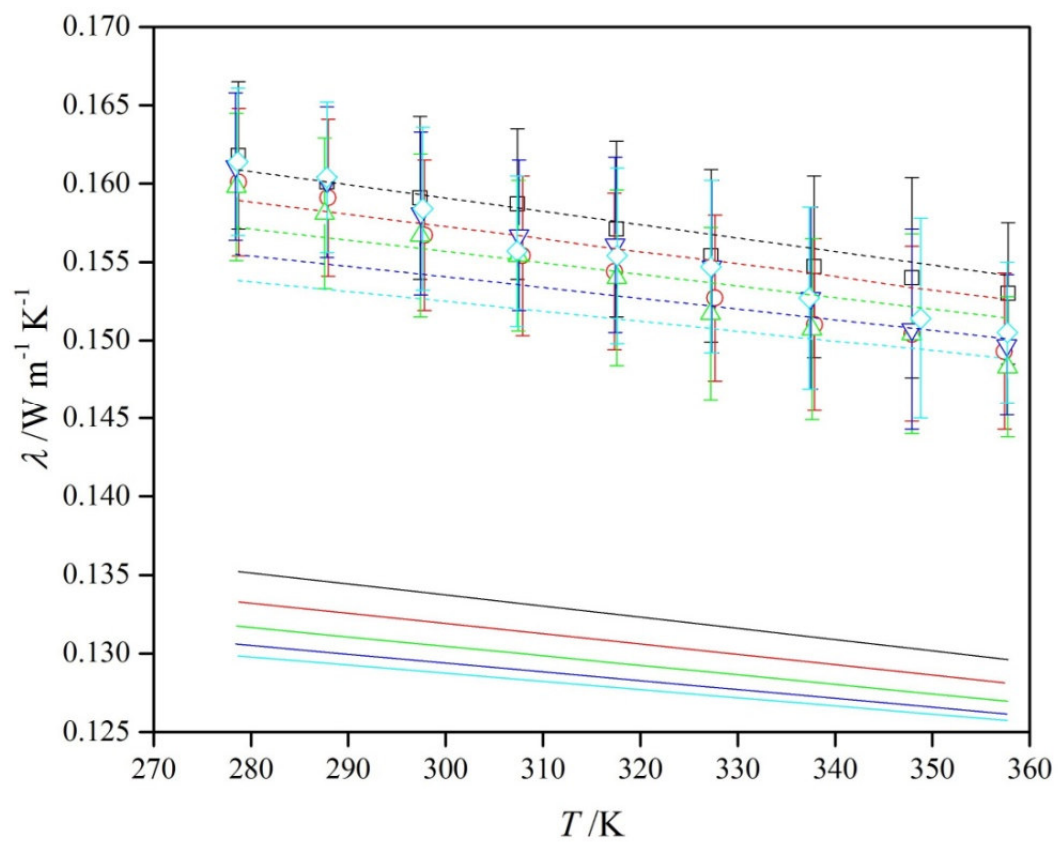

Figure 6 Thermal conductivity as a function of the temperature for:

$\square$ - experimental data of $\left[\mathrm{P}_{14,6,6,6}\right][\mathrm{AcO}]$; $\bigcirc$ - experimental data of $\left[\mathrm{P}_{14,6,6,6}\right][\mathrm{ButO}]$;

$\triangle$ - experimental data of $\left[\mathrm{P}_{14,6,6,6}\right][\mathrm{HexO}] ; \nabla$ - experimental data of $\left[\mathrm{P}_{14,6,6,6}\right][\mathrm{OctO}]$;

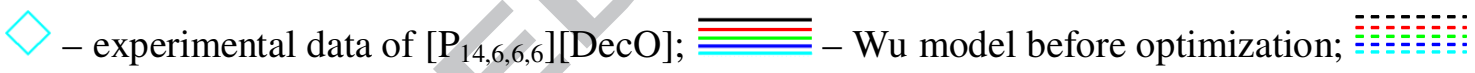

- Wu model after optimization. 


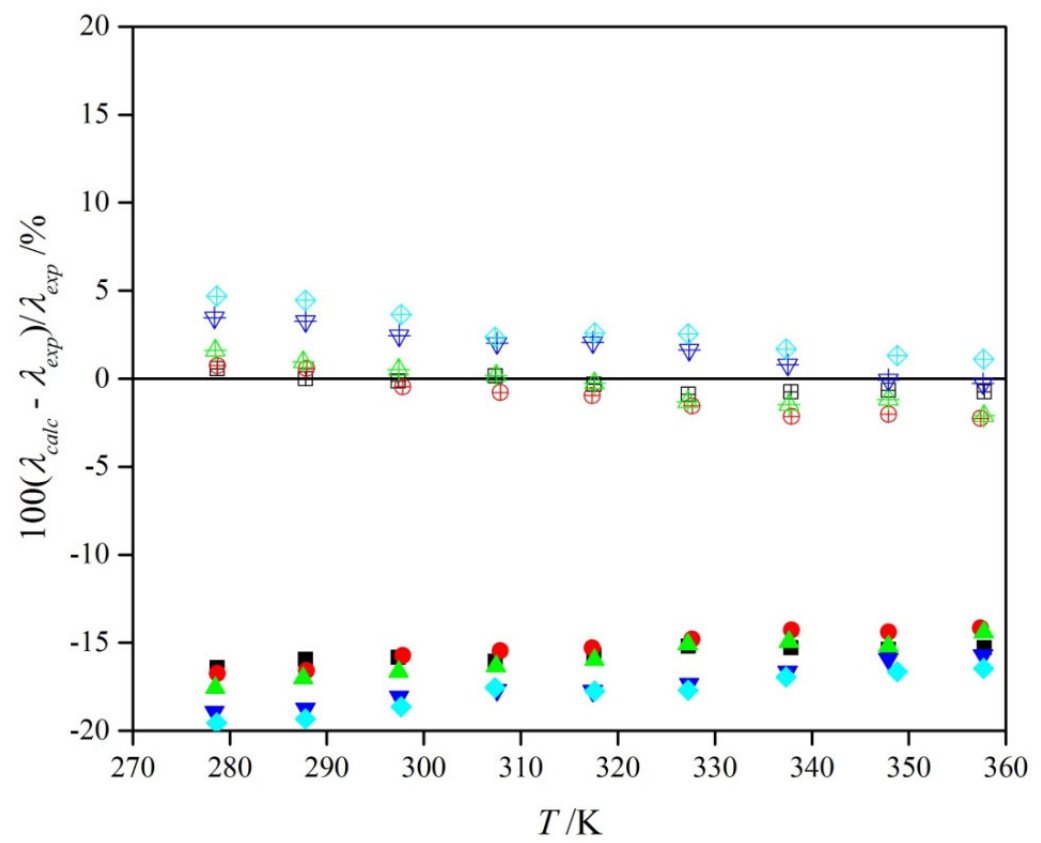

Figure 7 Relative deviations for thermal conductivity in case of: $\square \triangle \nabla>-$ Wu model before optimization; $\boxplus \oplus 4 \forall \vartheta-$ Wu model after optimization.

Table 1 Average absolute relative deviation (AARD) values of investigated ionic liquids thermal conductivity predictions, $T=(278-358) \mathrm{K}$, at atmospheric pressure.

\begin{tabular}{lll}
\hline & \multicolumn{2}{c}{ AARD /\% } \\
\cline { 2 - 3 } & $\begin{array}{l}\text { Wu model } \\
\text { before optimization }\end{array}$ & $\begin{array}{l}\text { Wu model } \\
\text { after optimization }\end{array}$ \\
\hline$\left[\mathrm{P}_{14,6,6,6}\right][\mathrm{AcO}]$ & 11.11 & 0.47 \\
{$\left[\mathrm{P}_{14,6,6,6}\right][\mathrm{ButO}]$} & 11.20 & 1.31 \\
{$\left[\mathrm{P}_{14,6,6,6}\right][\mathrm{HexO}]$} & 12.39 & 1.05 \\
{$\left[\mathrm{P}_{14,6,6,6}\right][\mathrm{OctO}]$} & 14.52 & 1.80 \\
{$\left[\mathrm{P}_{14,6,6,6}\right][\mathrm{DecO}]$} & 15.52 & 2.78
\end{tabular}

The deviations using the $\mathrm{Wu}$ model before optimization are negative values what may be caused by not insufficient anions with a range of carbon chain length being used to derive the model (Figure 7, Table S1). After the optimization, the deviations are close to $0 \%$, 
ranging from positive to negative values. However, to compare the model, overall AARDs was calculated as $16.42 \mathrm{Wu}$ model $[10,16,25]$.

The uncertainty of the measurement determined by the calibration procedure, $K \pm \delta K$, was $0.9932 \pm 0.0075$ (where $K$ is the calibration constant), what remains $1.50 \%$ deviation in case of the calibration constant, and mean $3.44 \%$ in case of measurement of $\left[\mathrm{P}_{14,6,6,6}\right][R \mathrm{O}]$ ILs. Nevertheless, the measurement uncertainty reported in the literature was observed to reach values up to $9 \%$ [52,54]. As can be seen, the AARDs are highly deviated when compared to the uncertainty of the measurement (before optimization). The maximum RD was found as $-19.54 \%$ for $\left[\mathrm{P}_{14,6,6,6}\right][\mathrm{DecO}]$ at $278.50 \mathrm{~K}$ (Table S1 and Figure 7). The smallest RD was found as $-14.17 \%$ for $\left[\mathrm{P}_{14,6,6,6}\right][\mathrm{ButO}]$ at $357.40 \mathrm{~K}$ for the $\mathrm{Wu}$ model. As can be seen, the maximum RD was found for the lowest temperature $(\sim 278 \mathrm{~K})$, however, the model included no data at these temperatures.

Another important relationship can be found for deviations between calculated and experimental results as a function of temperature (Figure 7) where for the $\mathrm{Wu}$ model before optimization the deviations for all ILs are similar. It may be caused by not accurate enough parametrization of $-\mathrm{CH}_{2}-$ group model which is the only one factor changing in investigated ILs. It can be observed also in Figure 8 where the results of thermal conductivity coefficient as a function of anion chain length are presented. Experimental data and values calculated with Wu model exhibited similar gradients which indicates that the prediction can be reliable (in the meaning of anion chain length dependence) while the re-optimization may solve this problem. The slight shifts with consistent slope in the dependence of anion chain length were achieved due to previously mentioned characterization of different $-\mathrm{CH}_{2}-$ group, in the meaning of ILs type (ammonium, phosphonium or others) [25]. 


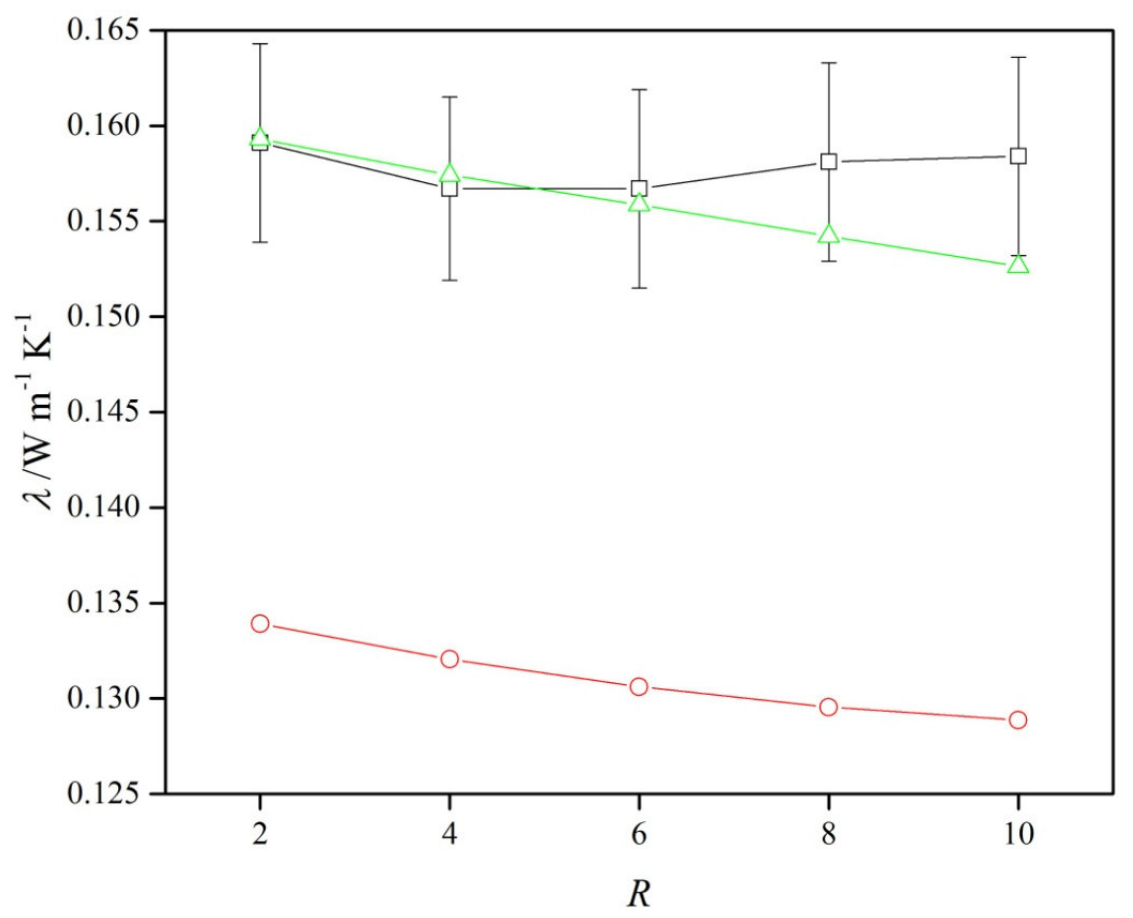

Figure 8 Thermal conductivity as a function of $\left[\mathrm{P}_{14,6,6,6}\right][R \mathrm{O}]$ anion chain length at $298.15 \mathrm{~K}$ for: $\square$ - experimental; $\bigcirc-$ Wu model before optimization; $\triangle_{- \text {Wu model after }}$ optimization.

The primary $\mathrm{Wu}$ model included only a few data points using quaternary phosphonium-based ILs (8 ILs with overall 54 data points). In general, the model showed a linear decrease in the thermal conductivity with increasing the chain length. As mentioned above, ILs with high molecular mass are very specific in the meaning of their critical properties due to their deviations from molecular solvents. As was shown by Valderrama et al. (2015) these properties exhibit deviations from linearity of critical parameters as function of molecular mass when compared to simple molecular solvents. This problem was solved by the introduction of mass connectivity index as a correction factor [22].

Group contribution methods are known for their simplicity to improve them and implement more data [55,56]. The only model which was discussed and fully based on this approach is $\mathrm{Wu}$ model. All data used to improve the Wu model are summarized in Table 2. 55 ILs were used including those based on imidazolium-, pyrrolidinium-, pyridinium-, 
phosphonium- and -ammonium cations. Overall 399 data points were used in the temperature range of $\left(273.15\right.$ - 390) K. Moreover, 9 ILs with molecular mass higher than $500 \mathrm{~g} \mathrm{~mol}^{-1}$ were used, and their critical parameters were calculated based on the methods proposed by Valderrama et al. (2015) [21]. As the thermal conductivity is a transport property, it seems to be reasonable to include the mass connectivity index and describe the connection between cation and anion. The availability of experimental data points for thermal conductivity is still very limited in the literature, thus, it affects the predictive models directly. Moreover, there is significant scatter for the values reported, e.g. for $\left[\mathrm{C}_{2} \mathrm{C}_{1} \mathrm{Im}\right]\left[\mathrm{NTf}_{2}\right]$ the thermal conductivity has been reported as $0.130 \mathrm{~W} \mathrm{~m}^{-1} \mathrm{~K}^{-1}(298 \mathrm{~K})$ [52] and $0.1202 \mathrm{~W} \mathrm{~m}^{-1} \mathrm{~K}^{-1}$ (298 K) [11]. Therefore, in order to select the data used for the model improvement/development a number of factors were considered including (i) the sample source, purification, purity and water content, treatment; (ii) the method used to determine the thermal conductivity (transient-hot wire vs parallel plate), and the associated uncertainties; (iii) the experimental data treatment and analysis including calibration, systematic errors reduction and statistical analysis. These three points are not negligible and must be always considered. For example, as was mentioned by Tomida et al. (2007) [57] and additionally highlighted by Wu et al. (2013) [25], the data in work of van Valkenburg et al. (2005) [2] cannot be reliable due to technique that was used which was a transient hot-wire measurement with a tantalum wire having a diameter of $0.052 \mathrm{~mm}$ and length of $25.3 \mathrm{~mm}$ and a heating rate of $30 \mathrm{~K} \mathrm{~s}^{-1}$.

The optimization was performed (as explained in 'Calculations' section) and the AARD values of the model for investigated ILs can be found in Table 1. As can be seen, the values are below the measurement uncertainty $(3.44 \%)$, with maximum for $\left[\mathrm{P}_{14,6,6,6}\right][\mathrm{DecO}]$ $2.78 \%$. The overall AARD for all data sets used is $1.66 \%$, with maximum AARD of $7.16 \%$ for 1,3-dibutylimidazolium bis[(trifluoromethyl)sulfonyl]imide. Wu et al. (2013) reported the same value of overall AARD, $1.66 \%$, while the maximum AARD was $11.0 \%$ [25]. The AARD of the model using the database from this work is $6.80 \%$. The results were also shown in Figure 9, including models before and after optimization. When the uncertainty of the method is taken into account, it can be assumed that the values produced by this method after optimization are satisfactory. Only eight points were out of this range which is only $2 \%$ of all database. The new group contribution model coefficients are reported in Table $\mathbf{3}$. The database used together with the calculations applied is included as a Microsoft Excel file in the supplementary information. 

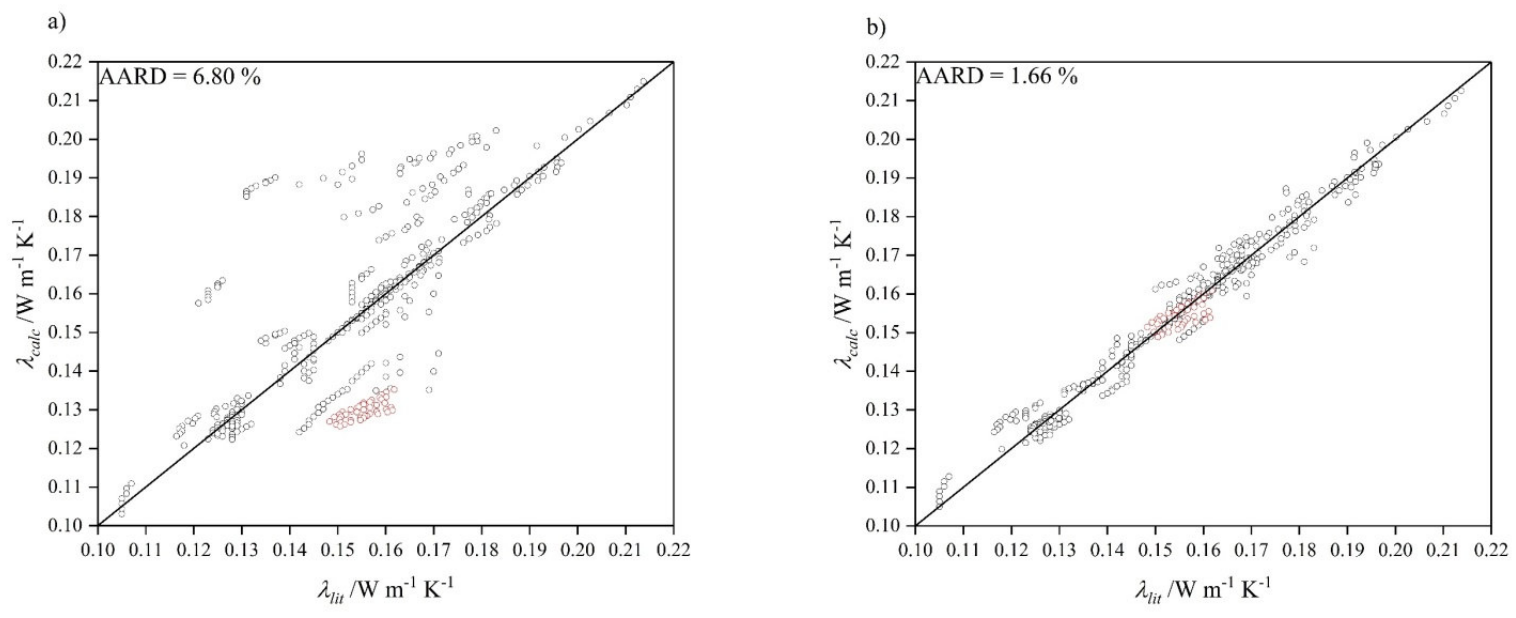

Figure 9 Linear relationship between experimental and calculated thermal conductivites for all sets of ionic liquids, a) - before and, b) - after optimization; black circles - training set, red circles - testing set (trihexyl(tetradecyl)phosphonium carboxylate ILs). 
Table 2 Summary of ILs data used for the thermal conductivity model improvement.

\begin{tabular}{|c|c|c|c|c|}
\hline Name & $T / \mathbf{K}$ & Amount of data & $M / \mathrm{g} \mathrm{mol}^{-1}$ & AARD /\% \\
\hline 1,2-dimethyl-3-propylimidazolium bis[(trifluoromethyl)sulfonyl]imide [2] & $300-390$ & 10 & 419.36 & 2.22 \\
\hline 1,3-dibutyl-imidazolium bis[(trifluoromethyl)sulfonyl]imide [11] & $293.15-353.15$ & 9 & 461.44 & -7.16 \\
\hline 1-butyl-1-methylpyrrolidinium bis[(trifluoromethyl)sulfonyl]imide [52] & $293-323$ & 4 & 422.41 & -0.69 \\
\hline 1-butyl-1-methylpyrrolidinium dicyanamide [58] & $293.5-343.4$ & 6 & 208.30 & -0.79 \\
\hline 1-butyl-1-methylpyrrolidinium tris(pentafluoroethyl)trifluorophosphate [52] & $293-353$ & 7 & 587.27 & -3.14 \\
\hline 1-butyl-3-methylimidazolium bis[(trifluoromethyl)sulfonyl]imide [52] & $293-353$ & 7 & 419.36 & -0.79 \\
\hline 1-butyl-3-methylimidazolium dicyanamide [58] & $293.6-344.2$ & 6 & 205.26 & -2.53 \\
\hline 1-butyl-3-methylimidazolium hexafluorophosphate [54] & $293-353$ & 7 & 284.18 & 1.47 \\
\hline 1-butyl-3-methylimidazolium tetracyanoborate [59] & $283.15-353.15$ & 8 & 254.10 & -1.76 \\
\hline 1-butyl-3-methylimidazolium tetrafluoroborate [57] & $294.2-334.3$ & 3 & 226.02 & 1.97 \\
\hline 1-butyl-3-methylimidazolium tricyanomethane [59] & $283.15-353.15$ & 8 & 229.28 & -3.17 \\
\hline 1-butyl-3-methylimidazolium trifluoromethanesulfonate [52] & $293-353$ & 7 & 288.29 & 0.51 \\
\hline 1-butylpyridinium tetrafluoroborate $[60]$ & $294.2-334.3$ & 3 & 223.02 & 3.04 \\
\hline 1-decyl-3-methylimidazolium bis[(trifluoromethyl)sulfonyl]imide [52] & $293-353$ & 7 & 503.52 & 3.00 \\
\hline 1-decyl-3-methylimidazolium tetracyanoborate [59] & $283.15-353.15$ & 8 & 338.26 & 1.79 \\
\hline 1-ethyl-3-methylimidazolium acetate [11] & $273.15-353.15$ & 9 & 170.21 & 0.95 \\
\hline 1-ethyl-3-methylimidazolium bis[(trifluoromethyl)sulfonyl]imide [52] & $293-353$ & 7 & 391.31 & 1.04 \\
\hline 1-ethyl-3-methylimidazolium dicyanamide [58] & $293.4-343.4$ & 6 & 177.21 & 4.10 \\
\hline 1-ethyl-3-methylimidazolium ethylsulfate [52] & $293-353$ & 7 & 236.29 & 0.45 \\
\hline 1-ethyl-3-methylimidazolium methylphosphonate [11] & $273.15-353.15$ & 9 & 205.18 & 1.77 \\
\hline 1-ethyl-3-methylimidazolium octylsulfate [11] & $273.15-353.15$ & 9 & 320.45 & 0.67 \\
\hline 1-ethyl-3-methylimidazolium tricyanomethanide $[11,59]$ & $273.15-353.15$ & 17 & 201.23 & 1.05 \\
\hline 1-hexyl-3-methylimidazolium bis[(trifluoromethyl)sulfonyl]imide [52] & $293-353$ & 7 & 447.42 & 0.41 \\
\hline 1-hexyl-3-methylimidazolium hexafluorophosphate $[20,54]$ & $293-353$ & 13 & 312.24 & 1.80 \\
\hline 1-hexyl-3-methylimidazolium tetracyanoborate [59] & $283.15-353.15$ & 8 & 282.15 & 1.05 \\
\hline 1-hexyl-3-methylimidazolium tetrafluoroborate [61] & $294.2-334.4$ & 3 & 226.02 & 1.50 \\
\hline 1-hexyl-3-methylimidazolium tricyanomethanide [59] & $283.15-353.15$ & 8 & 257.33 & 1.38 \\
\hline 1-hexylpyridinium tetrafluoroborate [60] & $294.2-334.3$ & 3 & 251.07 & 1.80 \\
\hline 1-octyl-3-methylimidazolium bis[(trifluoromethyl)sulfonyl]imide [52] & $293-353$ & 7 & 475.47 & 0.46 \\
\hline 1-octyl-3-methylimidazolium hexafluorophosphate [20] & $295.1-335.2$ & 3 & 340.29 & 2.20 \\
\hline 1-octyl-3-methylimidazolium tetracyanoborate [59] & $283.15-353.15$ & 8 & 310.21 & 3.18 \\
\hline 1-octyl-3-methylimidazolium tetrafluoroborate [61] & $294.2-334.3$ & 3 & 282.13 & 0.86 \\
\hline 1-octyl-3-methylimidazolium tricyanomethanide [59] & $283.15-353.15$ & 8 & 285.39 & 3.01 \\
\hline 1-octylpyridinium tetrafluoroborate $[60]$ & $294.2-334.3$ & 3 & 279.13 & 2.25 \\
\hline
\end{tabular}


3-decyl-1-methylimidazolium tricyanomethanide [59] butyltrimethylammonium bis[(trifluoromethyl)sulfonyl]imide [62] methyltrioctylammonium bis[(trifluoromethyl)sulfonyl]imide [11] tetrabutylphosphonium 2-aminoethanesulfonate [63]

tetrabutylphosphonium L-cysteinate [63]

tetrabutylphosphonium L-lysinate [63]

tetrabutylphosphonium L-prolinate [63]

tetrabutylphosphonium L-serinate [63]

tetrabutylphosphonium L-threoninate [63]

tetrabutylphosphonium L-valinate [63]

tributylmethylammonium 2-aminoethanesulfonate [63]

tributylmethylammonium L-lysinate [63]

tributylmethylammonium L-serinate [63]

tributylmethylammonium L-threoninate [63]

tributylmethylphosphonium methyl sulfate [64]

trihexyl(tetradecyl)phosphonium acetate

trihexyl(tetradecyl)phosphonium bis[(trifluoromethyl)sulfonyl]imide [52,64]

trihexyl(tetradecyl)phosphonium chloride [52]

trihexyl(tetradecyl)phosphonium decanoate

trihexyl(tetradecyl)phosphonium tris(pentafluoroethyl)trifluorophosphate [64]

trihexyltetradecylphosphonium bis(2,4,4-trimethylpentyl)phosphinate [64]

55 unique ILs

\begin{tabular}{llll}
$283.15-353.15$ & 8 & 313.44 & 1.00 \\
$296.69-332.21$ & 3 & 396.38 & 1.52 \\
$273.15-353.15$ & 9 & 648.85 & 0.83 \\
$298.15-353.15$ & 7 & 383.57 & 4.43 \\
$298.15-353.15$ & 7 & 379.58 & 0.14 \\
$298.15-353.15$ & 7 & 404.61 & 0.05 \\
$298.15-353.15$ & 7 & 373.55 & 0.08 \\
$298.15-353.15$ & 7 & 363.52 & 1.31 \\
$298.15-353.15$ & 7 & 377.54 & 0.25 \\
$313.15-353.15$ & 5 & 375.57 & 0.20 \\
$298.15-353.15$ & 7 & 324.52 & 0.28 \\
$298.15-353.15$ & 7 & 345.56 & 1.89 \\
$298.15-353.15$ & 7 & 304.47 & 0.21 \\
$298.15-353.15$ & 7 & 318.50 & 0.13 \\
$283.34-353.51$ & 9 & 328.45 & 1.84 \\
$278.70-357.78$ & 9 & 542.91 & 0.47 \\
$285.65-353$ & 14 & 764.00 & 2.36 \\
$293-353$ & 7 & 519.31 & 0.15 \\
$278.65-357.70$ & 9 & 655.13 & 2.78 \\
$282.19-355.07$ & 9 & 928.87 & 4.72 \\
$282.47-353.62$ & 9 & 773.27 & 1.85 \\
\hline $\mathbf{2 7 3 . 1 5 - 3 9 0}$ & $\mathbf{3 9 9}$ & $\mathbf{1 7 0 . 2 1 - 9 2 8 . 8 7}$ & $\mathbf{1 . 6 6}$
\end{tabular}


Table 3 New parameters for equation (1) in the Wu model (thermal conductivity).

\begin{tabular}{|c|c|c|}
\hline Group & \multirow{2}{*}{$\Delta \lambda_{0, j}$} & \multirow{2}{*}{ Amount of data points } \\
\hline Without rings & & \\
\hline$-\mathrm{CH}_{3}$ & 0.5929 & 396 \\
\hline$-\mathrm{CH}_{2}$ - (ammonium-based) & 0.101 & 40 \\
\hline$-\mathrm{CH}_{2}-$ (phosphonium-based) & 0.407 & 113 \\
\hline$-\mathrm{CH}_{2}-$ (with others) & 0.701 & 237 \\
\hline$>\mathrm{C}<$ & -0.467 & 165 \\
\hline$>\mathrm{CH}-$ & 1.927 & 63 \\
\hline$-\mathrm{CN}$ & 2.563 & 99 \\
\hline$-\mathrm{COO}-$ & 1.029 & 88 \\
\hline$>\mathrm{N}-/>\mathrm{N}^{+} /-\mathrm{N}_{-}^{-}$ & 5.28 & 130 \\
\hline$-\mathrm{NH}_{2}$ & 0.929 & 63 \\
\hline$-\mathrm{SO}_{2^{-}}^{-}$ & 7.54 & 130 \\
\hline$-\mathrm{O}-/[-\mathrm{O}]^{-}$ & -0.208 & 64 \\
\hline$-\mathrm{OH}$ & 1.925 & 28 \\
\hline$=\mathrm{O}$ & 0.323 & 18 \\
\hline$-\mathrm{F}$ & 1.3166 & 145 \\
\hline$-\mathrm{Cl}$ & 0.841 & 7 \\
\hline$-B$ & -1.04 & 50 \\
\hline$-\mathrm{P}$ & 3.2939 & 149 \\
\hline$-S-$ & 5.37 & 7 \\
\hline \multicolumn{3}{|l|}{ With rings } \\
\hline$=\mathrm{CH}-$ & -0.022 & 226 \\
\hline$-\mathrm{CH}_{2-}$ & 1.5145 & 24 \\
\hline$>\mathrm{CH}-$ & 2.055 & 7 \\
\hline -NH- & 0.547 & 7 \\
\hline$-\mathrm{N}=$ & 1.835 & 226 \\
\hline$>\mathrm{N}-/>\mathrm{N}<^{+}$ & 0.042 & 234 \\
\hline \multicolumn{3}{|l|}{ Coefficients } \\
\hline$k_{0}$ & \multirow{4}{*}{\multicolumn{2}{|c|}{$\begin{array}{l}372.98 \cdot 10^{-2} \\
646.97 \cdot 10^{-4} \\
-1871.59 \cdot 10^{-6} \\
25.85 \cdot 10^{-6}\end{array}$}} \\
\hline$a_{0}$ & & \\
\hline & & \\
\hline$a_{2}$ & & \\
\hline
\end{tabular}

\section{Heat capacity}

As discussed above, the $\mathrm{P}^{+} / \mathrm{N}^{+}$centres lead to significant differences in the charge distribution on the bound alkyl chain. For this reason, the charge effect was included in the structure characterization for heat capacity prediction to correctly reproduce the group contribution methodology.

The results of heat capacity prediction are summarised in Table $\mathbf{S 2}$, and presented in Figure 10. The Ge-Nancarrow model does not include any information about connections but divides the structure into characteristic groups (as group contribution methods) for both cation and anion without distinction on the charge type or place on the molecule, as in Joback method. As can be seen, the predicted values have increasingly large deviations from the experimental data with increasing the anion chain length using the model. It is expected that 
the heat capacity increases with anion chain length which is observed in the experimental and predicted data. The calculated overall AARD is $2.14 \%$. The maximum determined RD is $5.66 \%$ for $\left[\mathrm{P}_{14,6,6,6}\right][\mathrm{DecO}]$ at $293.15 \mathrm{~K}$. While the minimum $\mathrm{RD}$ is $-0.05 \%$ for $\left[\mathrm{P}_{14,6,6,6}\right][\mathrm{ButO}]$ at $358.15 \mathrm{~K}$, as shown in Figure 11. The AARD values are reported in Table 4. As can be seen, the Ge-Nancarrow model estimated the AARD values of heat capacity below $5 \%$ for all ILs. The uncertainty of the experimental measurements of heat capacity have been reported to be higher than $10 \%$ in some works but [65-67], more commonly, are up to $3 \%$ [68-70]. Thus, the capability of well-working model is assessed as the AARD below $3 \%$.

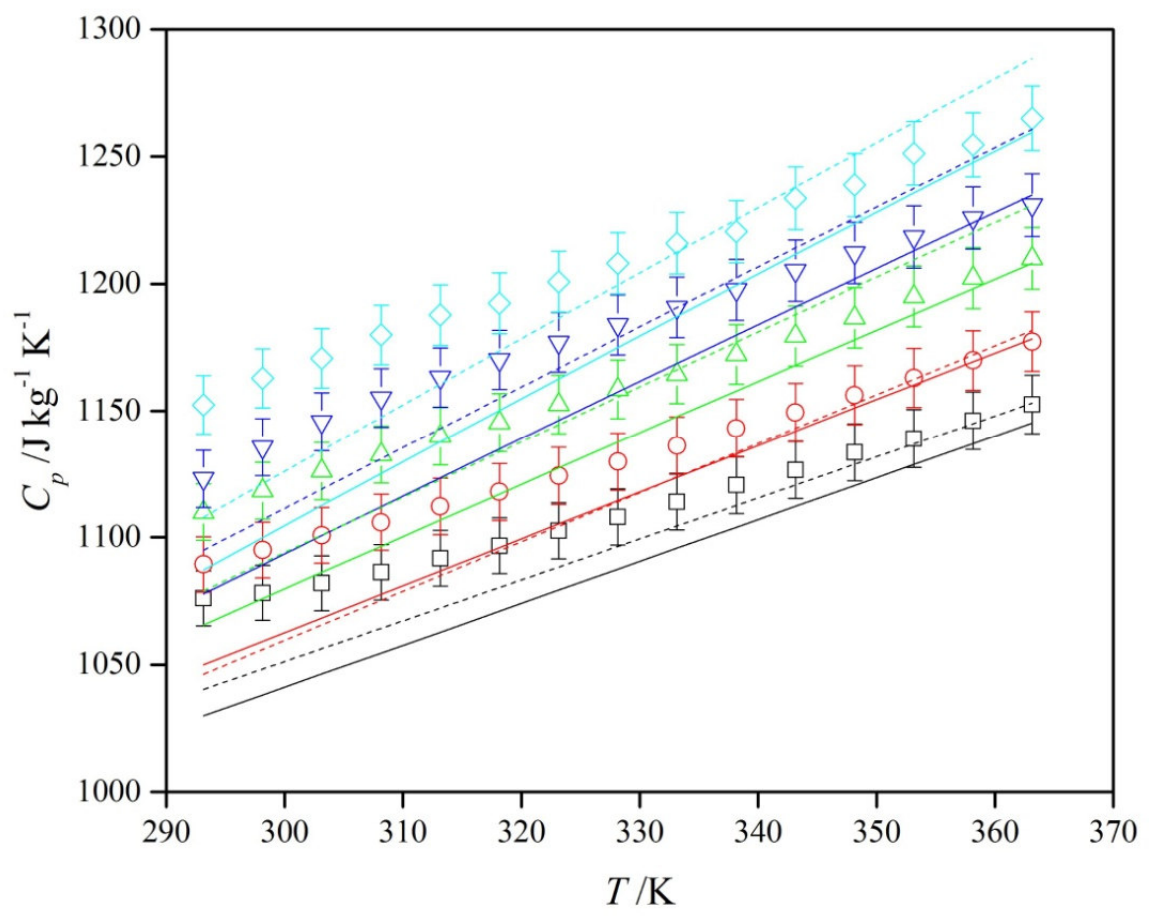

Figure 10 Heat capacity as a function of the temperature for:

$\square$ - experimental data of $\left[\mathrm{P}_{14,6,6,6}\right][\mathrm{AcO}] ; \bigcirc_{-}$experimental data of $\left[\mathrm{P}_{14,6,6,6}\right][\mathrm{ButO}]$; - experimental data of $\left[\mathrm{P}_{14,6,6,6}\right][\mathrm{HexO}] ; \nabla$ - experimental data of $\left[\mathrm{P}_{14,6,6,6}\right][\mathrm{OctO}]$;

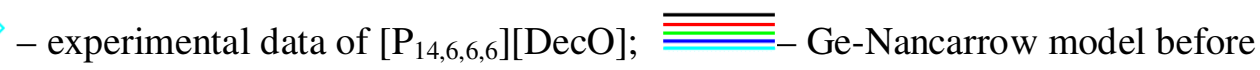
optimization; 


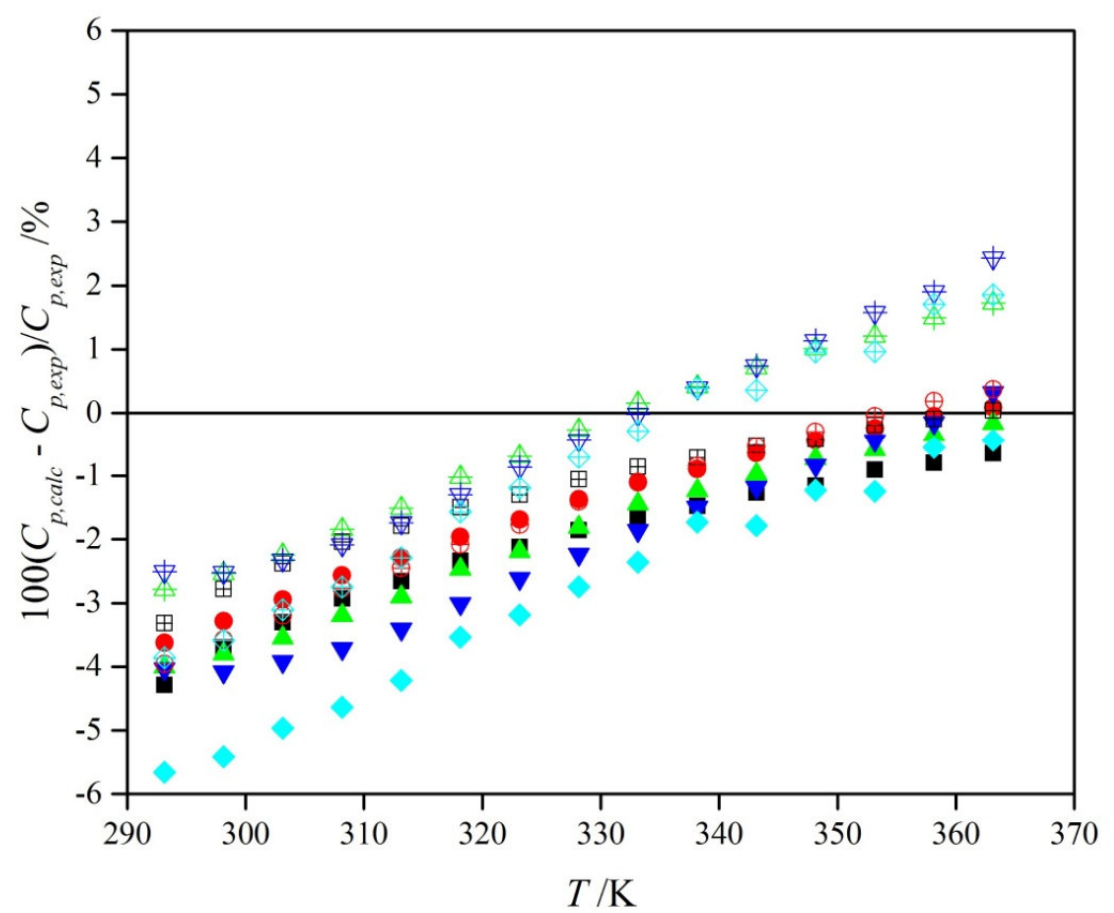

Figure 11 Relative deviations for thermal conductivity in case of: $\square \triangle \nabla>-\mathrm{Ge}$ Nancarrow model before optimization; $\boxplus \oplus 4 \forall \diamond$ - Ge-Nancarrow model after optimization. 
Table 4 Average absolute relative deviation (AARD) values of investigated ionic liquids and models (heat capacity), $T=(293-363) \mathrm{K}$, at atmospheric pressure.

\begin{tabular}{|c|c|c|}
\hline & \multicolumn{2}{|l|}{ AARD /\% } \\
\hline & Ge-Nancarrow model & Ge-Nancarrow model \\
\hline & before optimization & after optimization \\
\hline$\left[\mathrm{P}_{14,6,6,6}\right][\mathrm{AcO}]$ & 2.07 & 1.26 \\
\hline$\left[\mathrm{P}_{14,6,6,6}\right][\mathrm{ButO}]$ & 1.55 & 1.64 \\
\hline$\left[\mathrm{P}_{14,6,6,6}\right][\mathrm{HexO}]$ & 1.96 & 1.31 \\
\hline$\left[\mathrm{P}_{14,6,6,6}\right][\mathrm{OctO}]$ & 2.22 & 1.46 \\
\hline$\left[\mathrm{P}_{14,6,6,6}\right][\mathrm{DecO}]$ & 2.91 & 1.70 \\
\hline
\end{tabular}

The deviations for the Ge-Nancarrow model remain similar what may indicate the propagation of the same error, e.g. the $-\mathrm{CH}_{2}$ - group characterization, with $\left[\mathrm{P}_{14,6,6,6}\right][\mathrm{DecO}]$ as an exception. The heat capacity as a function of anion chain length is presented in Figure 12. The heat capacity depends almost linearly with the anion chain length and a similar dependence was found for the model before and after optimization. Otherwise, a deviation can be easily observed and may be originated from small amount of data for carboxylate anions used to establish the parameters. 


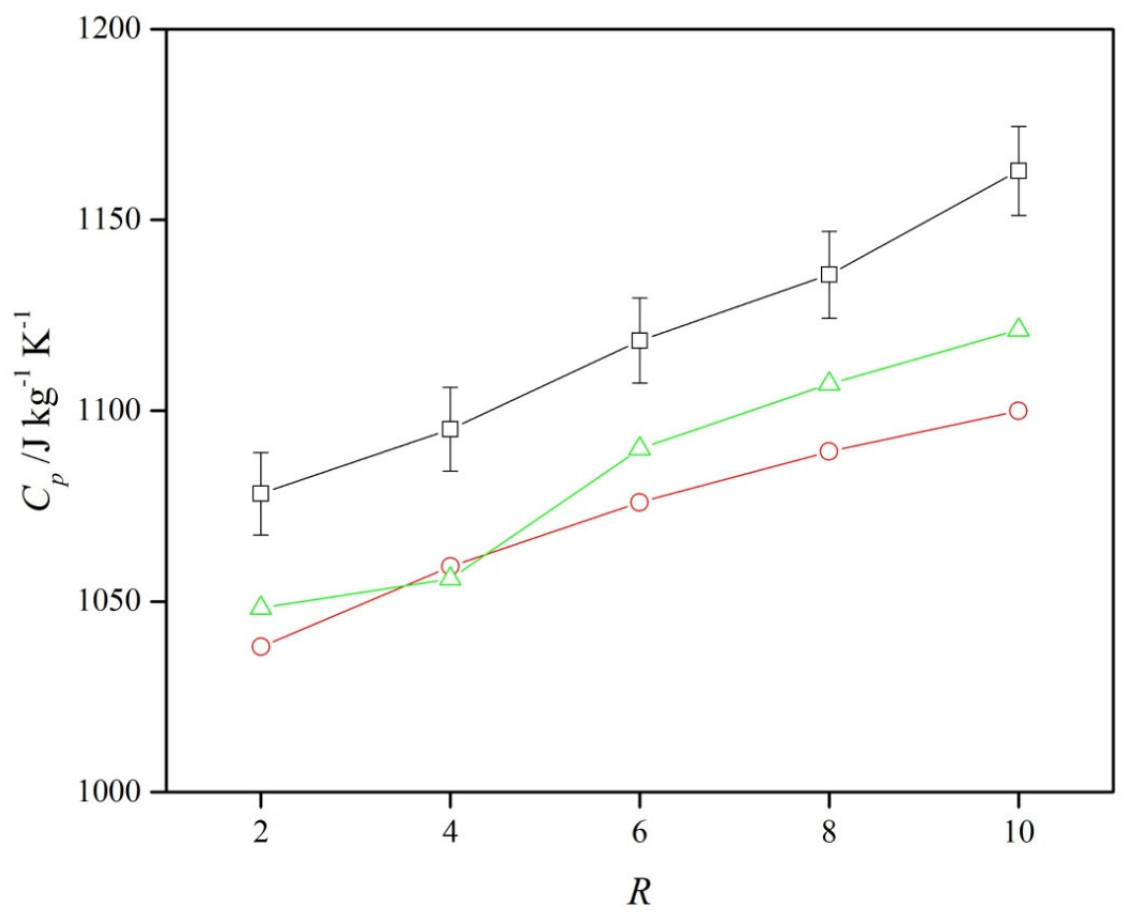

Figure 12 Heat capacity as a function of $\left[\mathrm{P}_{14,6,6,6}\right][R \mathrm{O}]$ anion chain length at $298.15 \mathrm{~K}$ for: $\square_{\text {- experimental; }} \bigcirc_{-}$Ge-Nancarrow model before optimization; $\triangle_{-}$Ge-Nancarrow model.

The summary of data sets used for the improvement are reported in Table 5. 3646 data points from 103 ILs were used in the temperature range of $(190$ - 520) K, including those based on imidazolium, pyrrolidinium, pyridinium, phosphonium, ammonium cations. While in the original Ge-Nancarrow model 2642 data points from 96 ILs were used. The described method including the charge distribution was applied in the present work. The availability of heat capacity data in the literature is well-developed, however, different qualities can be observed with very distinctive deviations. The purity (particularly the water content), purity assessment, measurement methodology or measurement uncertainty were taken into account. Similar approach was used as in Nancarrow et al. (2015) to reduce the impact of one IL's data into the modelling [17]. For example, a large number of data points for $\left[\mathrm{C}_{4} \mathrm{C}_{1} \mathrm{Im}\right]\left[\mathrm{PF}_{6}\right]$ originated from one source [71]. Thus, the data sets were selected to consist of no more than $5 \%$ of the total number of data points utilised. Similar data 
discrimination process was used as for the thermal conductivity model optimisation, herein, and in the study by Nancarrow et al. (2015).

AARD values of the model after optimization are reported in Table 4. It was possible to achieve AARD lower than $2 \%$, with a maximum of $1.70 \%$ for $\left[\mathrm{P}_{14,6,6,6}\right][\mathrm{DecO}]$. The overall AARD including all data points is $4.28 \%$ which indicates a high prediction ability, in comparison to the measurement uncertainty. Ge-Nancarrow et al. (2015) reported an overall AARD of $6.27 \%$ (using the original database) or $12.57 \%$ using the database in this work. Significantly high deviations were observed for 1-ethyl-3-methylimidazolium thiocyanate [72], 1-methyl-3-propylpyrrolidinium bis[(trifluoromethyl)sulfonyl]imide [73], 1-butyl-3methylimidazolium thiocyanate [72], 1-hexylquinolinium bis[(trifluoromethyl)sulfonyl]imide [74], tributylmethylammonium L-lysinate [63]. This may be caused by the measurement error. The results from the Ge-Nancarrow model before (using the dataset in this work) and after optimization are shown in Figure 13. The original and new model parameters are reported in Table 6. Nevertheless, the prediction for $\left[\mathrm{P}_{14,6,6,6}\right][\mathrm{RO}]$ is better after reoptimization (Figure 12), it is still out of the uncertainty range. However, the general prediction capability is better for all data.
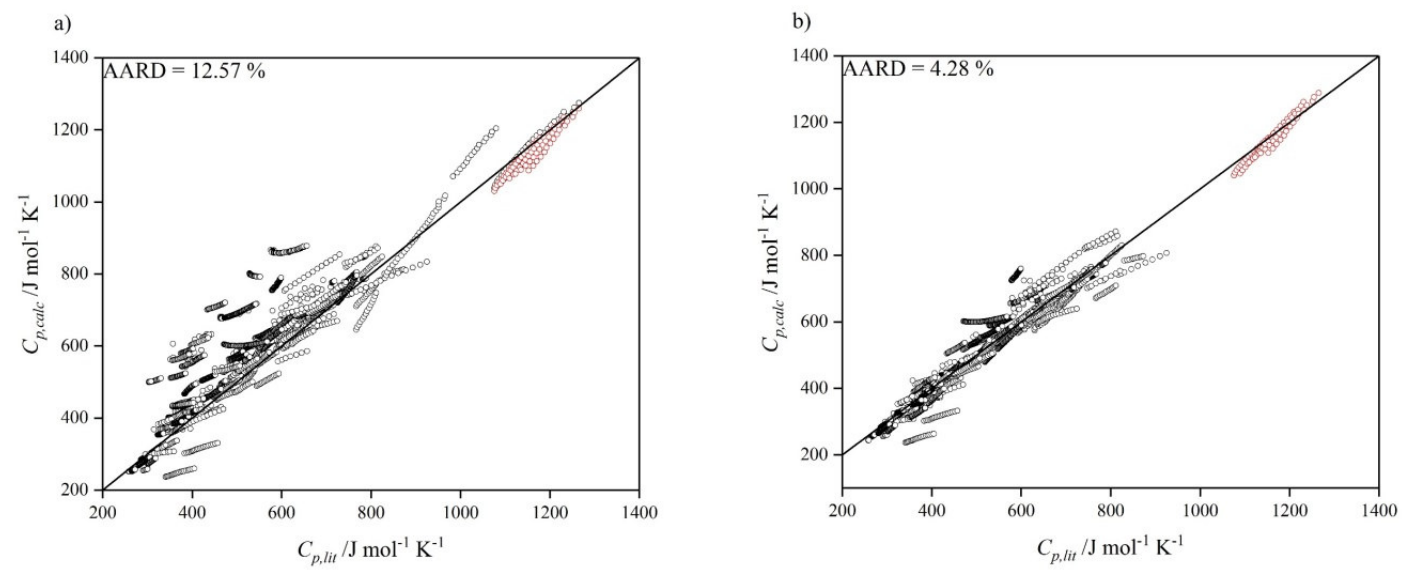

Figure 13 Linear relationship between experimental and calculated heat capacity for all sets of ionic liquids, a) - before and, b) - after optimization; black circles - training set, red circles - testing set (trihexyl(tetradecyl)phosphonium carboxylate ILs). 
Table 5 Summary of ILs data used for the heat capacity model improvement.

\begin{tabular}{|c|c|c|c|c|}
\hline Name & $T / \mathbf{K}$ & Amount of data & $M / \mathrm{g} \mathrm{mol}^{-1}$ & AARD /\% \\
\hline 2-hydroxy-N-methylethanaminium propionate [75] & $287.15-326.15$ & 111 & 148.2 & 0.35 \\
\hline 1-(2-hydroxyethyl)-3-methylimidazolium 2,2,2-trifluoroacetate [76] & $283.15-343.15$ & 7 & 240.2 & 11.24 \\
\hline 1,3-dimethylimidazolium methylsulfate [77] & $318.15-368.15$ & 6 & 208.2 & 5.68 \\
\hline 1-butyl-1-methylpyrrolidinium bis[(trifluoromethyl)sulfonyl]imide $[14,78]$ & $237.44-368.4$ & 85 & 422.4 & 2.55 \\
\hline 1-butyl-1-methylpyrrolidinium tris(pentafluoroethyl)trifluorophosphate [14] & $293-358$ & 14 & 573.3 & 12.63 \\
\hline 1-butyl-2,3-dimethylimidazolium tetrafluoroborate $[80,81]$ & $313.2-383.2$ & 17 & 240.1 & 5.54 \\
\hline 1-butyl-2-methylpyridinium tetrafluoroborate [82] & $288.15-338.15$ & 21 & 237.1 & 1.01 \\
\hline 1-butyl-3-cyanopyridinium bis[(trifluoromethyl)sulfonyl]imide [83] & $298.15-353.15$ & 3 & 441.4 & 7.22 \\
\hline 1-butyl-3-methylimidazolium acetate $[84,85]$ & $210-413.15$ & 32 & 198.3 & 5.43 \\
\hline 1-butyl-3-methylimidazolium bis(oxalato)borate [86] & $244.30-292.74$ & 50 & 326.1 & 9.87 \\
\hline 1-butyl-3-methylimidazolium bis[(trifluoromethyl)sulfonyl]imide $[80,87,88]$ & $190-328.15$ & 32 & 419.4 & 0.65 \\
\hline 1-butyl-3-methylimidazolium bromide $[80,81,89-91]$ & $225.62-403.2$ & 57 & 219.1 & 5.56 \\
\hline 1-butyl-3-methylimidazolium dicyanamide $[65,78,80,92,93]$ & $235.8-372.2$ & 156 & 205.3 & 4.40 \\
\hline 1-butyl-3-methylimidazolium hexafluorophosphate $[80,88]$ & $283.15-323.15$ & 10 & 284.2 & 8.55 \\
\hline 1-butyl-3-methylimidazolium iodide [94,95] & $209.86-370$ & 134 & 266.1 & 1.56 \\
\hline 1-butyl-3-methylimidazolium methylsulfate $[69,96,97]$ & $293.15-318.15$ & 18 & 250.3 & 0.57 \\
\hline 1-butyl-3-methylimidazolium octylsulfate [98] & $298.15-343.15$ & 46 & 348.5 & 2.06 \\
\hline 1-butyl-3-methylimidazolium phenolate [99] & $303.15-353.15$ & 11 & 220.3 & 6.38 \\
\hline
\end{tabular}


1-butyl-3-methylimidazolium tetrafluoroborate $[73,80,90,100]$

\begin{tabular}{|c|c|c|c|}
\hline $278.15-358.15$ & 40 & 226.0 & 2.44 \\
\hline $296.2-372.2$ & 20 & 197.3 & 24.19 \\
\hline $190-370$ & 21 & 252.2 & 1.00 \\
\hline $292.86-425.15$ & 162 & 288.3 & 2.18 \\
\hline $293.1-333.1$ & 41 & & 7.12 \\
\hline $323.1-353.1$ & 31 & & 1.06 \\
\hline $296.2-372.2$ & 20 & 430.4 & 8.04 \\
\hline $323.18-423.15$ & & 416.4 & 3.19 \\
\hline 284.33 & 41 & 223 & 8.63 \\
\hline $298.15-338.15$ & 17 & 285.3 & 9.02 \\
\hline $303.15-353.15$ & 11 & 304.5 & 1.78 \\
\hline $309.15-323.15$ & 4 & 405.4 & 12.53 \\
\hline 298.15 & 1 & 170.2 & 6.22 \\
\hline $256.91-463.15$ & 72 & 391.3 & 1.68 \\
\hline $347.66-367.5$ & 16 & 191.1 & 4.37 \\
\hline $298.15-358.2$ & 13 & 177.2 & 1.65 \\
\hline $190-389.95$ & 208 & 236.3 & 1.79 \\
\hline $288.15-343.15$ & 11 & 222.3 & 6.05 \\
\hline $283.15-358.15$ & 28 & 198.0 & 1.09 \\
\hline $296.2-372.2$ & 20 & 169.3 & 32.42 \\
\hline $283.15-425.15$ & 77 & 260.2 & 1.19 \\
\hline $293.1-333.1$ & 82 & 402.3 & 6.99 \\
\hline
\end{tabular}

1-butyl-3-methylimidazolium thiocyanate [72]

1-butyl-3-methylimidazolium trifluoroacetate [85]

1-butyl-3-methylimidazolium trifluoromethanesulfonate $[14,65,69,78,80,96,97,101]$

1-butyl-3-methylpyridinium bis[(trifluoromethyl)sulfonyl]imide [65]

1-butyl-3-methylpyridinium trifluoromethanesulfonate [102]

1-butyl-4-methylpyridinium bis[(trifluoromethyl)sulfonyl]imide [65]

1-butylpyridinium bis[(trifluoromethyl)sulfonyl]imide [101]

1-butylpyridinium tetrafluoroborate [103]

1-butylpyridinium trifluoromethanesulfonate [82]

1-decyl-3-methylimidazolium phenolate [99]

1-ethyl-2,3-dimethylimidazolium bis[(trifluoromethyl)sulfonyl]imide [80]

1-ethyl-3-methylimidazolium acetate [104]

1-ethyl-3-methylimidazolium bis[(trifluoromethyl)sulfonyl]imide [67,73,80,91,105]

1-ethyl-3-methylimidazolium bromide [91]

1-ethyl-3-methylimidazolium dicyanamide [104,106]

1-ethyl-3-methylimidazolium ethylsulfate $[69,96,97,107]$

1-ethyl-3-methylimidazolium methylsulfate [76,104,108]

1-ethyl-3-methylimidazolium tetrafluoroborate [73,109-111]

1-ethyl-3-methylimidazolium thiocyanate [72]

1-ethyl-3-methylimidazolium trifluoromethanesulfonate $[69,76,97,101]$

1-ethyl-3-methylpyridinium bis[(trifluoromethyl)sulfonyl]imide [65]

$293.1-333.1 \quad 82$

6.99 
1-ethyl-3-methylpyridinium ethylsulfate [102]

1-ethylpyridinium bis[(trifluoromethyl)sulfonyl]imide [112]

1-ethylpyridinium bromide [113]

1-heptyl-3-methylimidazolium bis[(trifluoromethyl)sulfonyl]imide [114]

1-hexyl-2,3-dimethylimidazolium bis[(trifluoromethyl)sulfonyl]imide [102]

1-hexyl-3,5-dimethylpyridinium bis[(trifluoromethyl)sulfonyl]imide [102]

1-hexyl-3-methylimidazolium bis(oxalato)borate [86]

1-hexyl-3-methylimidazolium bis[(trifluoromethyl)sulfonyl]imide [101,102,115,116]

1-hexyl-3-methylimidazolium bromide [102]

1-hexyl-3-methylimidazolium hexafluorophosphate [117]

1-hexyl-3-methylimidazolium phenolate [99]

1-hexyl-3-methylimidazolium tetrafluoroborate $[69,96,97,102,118]$

1-hexyl-3-methylimidazolium trifluoromethanesulfonate [101]

1-hexyl-3-methylimidazolium tris(pentafluoroethyl)trifluorophosphate [117]

1-hexyl-3-methylpyridinium bis[(trifluoromethyl)sulfonyl]imide [102,119]

1-hexyl-4-cyanopyridinium bis[(trifluoromethyl)sulfonyl]imide [83]

1-hexylpyridinium bis[(trifluoromethyl)sulfonyl]imide [102]

1-hexylquinolinium bis[(trifluoromethyl)sulfonyl]imide [74]

1-methyl-1-octylpyrrolidinium bis[(trifluoromethyl)sulfonyl]imide [66]

1-methyl-1-propylpiperidinium bis[(trifluoromethyl)sulfonyl]imide [120]

1-methyl-3-octylimidazolium phenolate [99]

1-methyl-3-octylimidazolium tetrafluoroborate [102,107,118,121]

\begin{tabular}{|c|c|c|c|}
\hline $298-323$ & 2 & 247.3 & 4.74 \\
\hline $288.15-338.15$ & 21 & 388.3 & 6.77 \\
\hline $397.31-409.65$ & 5 & 188.1 & 12.68 \\
\hline 298.15 & 1 & 461.5 & 2.65 \\
\hline $298-323$ & 2 & 461.5 & 0.32 \\
\hline $298-323$ & 2 & & 13.71 \\
\hline $239.33-397.44$ & 80 & 354.1 & 10.55 \\
\hline $190-425.15$ & 250 & 447.4 & 1.46 \\
\hline $298-323$ & & 247.2 & 5.81 \\
\hline $293.15-343.15$ & 51 & 312.2 & 1.86 \\
\hline $303.15-353.15$ & 11 & 248.4 & 4.96 \\
\hline $283.15-323.15$ & 24 & 254.1 & 0.71 \\
\hline $313.14-425.15$ & 64 & 330.4 & 1.03 \\
\hline $293.15-343.15$ & 51 & 612.3 & 2.31 \\
\hline $298-323$ & 2 & 458.5 & 6.37 \\
\hline $298.15-353.15$ & 3 & 469.4 & 11.26 \\
\hline $298-323$ & 2 & 444.4 & 1.42 \\
\hline $321.52-370.13$ & 79 & 494.5 & 25.58 \\
\hline $265.06-385.14$ & 13 & 478.5 & 11.75 \\
\hline $298-520$ & 24 & 422.4 & 1.84 \\
\hline $303.15-353.15$ & 11 & 276.4 & 5.86 \\
\hline $192.85-370$ & 132 & 282.1 & 0.22 \\
\hline
\end{tabular}


1-methyl-3-pentylimidazolium bis[(trifluoromethyl)sulfonyl]imide [114]

\begin{tabular}{|c|c|c|c|}
\hline 298.15 & 1 & 433.4 & 1.39 \\
\hline $283.15-358.15$ & 41 & 405.4 & 7.29 \\
\hline $218.48-367.18$ & 39 & 205.1 & 5.13 \\
\hline $298-323$ & 2 & 475.5 & 8.54 \\
\hline $313.17-425.15$ & 64 & & 1.59 \\
\hline $298-323$ & 2 & 486.5 & 9.98 \\
\hline $265.04-385.13$ & 13 & 472.5 & 7.63 \\
\hline $330.91-400$ & 50 & 295.2 & 1.02 \\
\hline $351.39-397.71$ & 16 & 202.1 & 9.91 \\
\hline $278.15-338.15$ & 25 & 209 & 11.54 \\
\hline $360.15-400.15$ & 9 & 241.4 & 1.33 \\
\hline $286.15-336.15$ & 92 & 162.2 & 3.26 \\
\hline $283.15-333.15$ & 107 & 176.2 & 0.34 \\
\hline $278.15-338.15$ & 25 & 416.4 & 1.00 \\
\hline $278.15-343.15$ & 14 & 300.5 & 1.15 \\
\hline $298.15-353.15$ & 3 & 469.4 & 0.74 \\
\hline $244.24-357.68$ & 58 & 271.3 & 16.94 \\
\hline $293.1-333.1$ & 41 & 416.4 & 6.61 \\
\hline $315.15-425.15$ & 23 & 487.5 & 0.69 \\
\hline $323.46-339.26$ & 10 & 398.6 & 7.28 \\
\hline $360.15-390.15$ & 7 & 255.4 & 2.21 \\
\hline $278.32-367.93$ & 48 & 396.4 & 3.68 \\
\hline
\end{tabular}

1-methyl-3-propylimidazolium bis[(trifluoromethyl)sulfonyl]imide [122]

1-methyl-3-propylimidazolium bromide [95]

1-octyl-3-methylimidazolium bis[(trifluoromethyl)sulfonyl]imide [102]

1-octyl-3-methylimidazolium trifluoromethanesulfonate [101]

1-octyl-3-methylpydridinium bis[(trifluoromethyl)sulfonyl]imide [102]

1-octylpyridinium bis[(trifluoromethyl)sulfonyl]imide [66]

1-pentylpyridinium hexafluorophosphate [123]

1-propylpyridinium bromide [113]

1-propylpyridinium tetrafluoroborate [124]

2-hydroxy-N,N,N-trimethyl-ethanaminium 1-butylsulfate [125]

2-hydroxy-N-methylethanaminium butanoate [75]

2-hydroxy-N-methylethanaminium pentanoate [75]

2-methyl-1-propylpyridinium bis[(trifluoromethyl)sulfonyl]imide [126]

2-octylisoquinolinium thiocyanate [127]

3-cyano-1-octylpyridinium bis[(trifluoromethyl)sulfonyl]imide [83]

3-methyl-1-propylimidazolium (S)-2-amino-4-carboxybutanoate [128]

3-methyl-1-propylpyridinium bis[(trifluoromethyl)sulfonyl]imide [65]

4-(dimethylamino)-1-hexyl-pyridinium bis[(trifluoromethyl)sulfonyl]imide [101]

4,6-dimethyl-N-phenylpyrimidin-2-amine dodecanoate [129]

butylethyldimethylammonium ethylsulfate [125]

butyltrimethylammonium bis[(trifluoromethyl)sulfonyl]imide [78]

396.4

.39

29

59

.98

.63

.02

1.54

.26

.34

0.74

16.94

6.61

69

.21 
N-(2-hydroxyethyl)-N,N-dimethylbutanaminium bromide [68]

\begin{tabular}{|c|c|c|c|}
\hline $409.71-438.26$ & 19 & 226.2 & 7.33 \\
\hline $386.41-403.35$ & 13 & 254.2 & 1.86 \\
\hline $382.50-429.98$ & 48 & 212.1 & 0.80 \\
\hline $313.13-425.15$ & 64 & 459.4 & 4.02 \\
\hline $355.15-395.15$ & 9 & & 2.83 \\
\hline $313.12-423.17$ & 23 & & 1.54 \\
\hline $300.15-375.15$ & 16 & 243.3 & 3.03 \\
\hline $278.15-328.15$ & 21 & 293.2 & 14.50 \\
\hline $293.15-363.15$ & 9 & 363.5 & 7.64 \\
\hline $293.15-363.15$ & 9 & 375.6 & 9.22 \\
\hline $293.15-363.15$ & 9 & 345.6 & 10.94 \\
\hline $293.15-363.15$ & 9 & 304.5 & 0.16 \\
\hline $293.15-363.15$ & 9 & 318.5 & 7.21 \\
\hline $343.15-463.15$ & 50 & 328.5 & 0.47 \\
\hline $298.15-305.15$ & 8 & 466.5 & 2.08 \\
\hline $298.15-305.15$ & 8 & 494.6 & 1.35 \\
\hline $293.15-363.15$ & 15 & 519.3 & 1.26 \\
\hline $293.15-363.15$ & 15 & 655.1 & 1.70 \\
\hline $190-520$ & 3646 & $148.18-655.12$ & 4.28 \\
\hline
\end{tabular}

$\mathrm{N}$-(2-hydroxyethyl)-N,N-dimethylhexan-1-aminium bromide [68]

$\mathrm{N}$-(2-hydroxyethyl)-N,N-dimethylpropanaminium bromide [68]

n-butyl-4-(n',n'-dimethylammonium)pyridinium bis[(trifluoromethyl)sulfonyl]imide [101]

N-ethyl-2-hydroxy-N,N-dimethylethanaminium octylsulfate [125]

n-ethyl-4-(n',n'-dimethylammonium)pyridinium bis[(trifluoromethyl)sulfonyl]imide [101

N-ethyl-N-(2-hydroxyethyl)-N,N-dimethylammonium ethylsulfate [125]

N-octyl-3-methylpyridinium tetrafluoroborate [82]

tetrabutylphosphonium L-serinate [63]

tetrabutylphosphonium L-valinate [63]

tributylmethylammonium L-lysinate [63]

tributylmethylammonium L-serinate [63]

tributylmethylammonium L-threoninate [63]

tributylmethylphosphonium methylsulfate [67]

triethylhexylammonium bis[(trifluoromethyl)sulfonyl]imide [130]

triethyloctylammonium bis[(trifluoromethyl)sulfonyl]imide [130]

trihexyl(tetradecyl)phosphonium acetate

trihexyl(tetradecyl)phosphonium decanoate
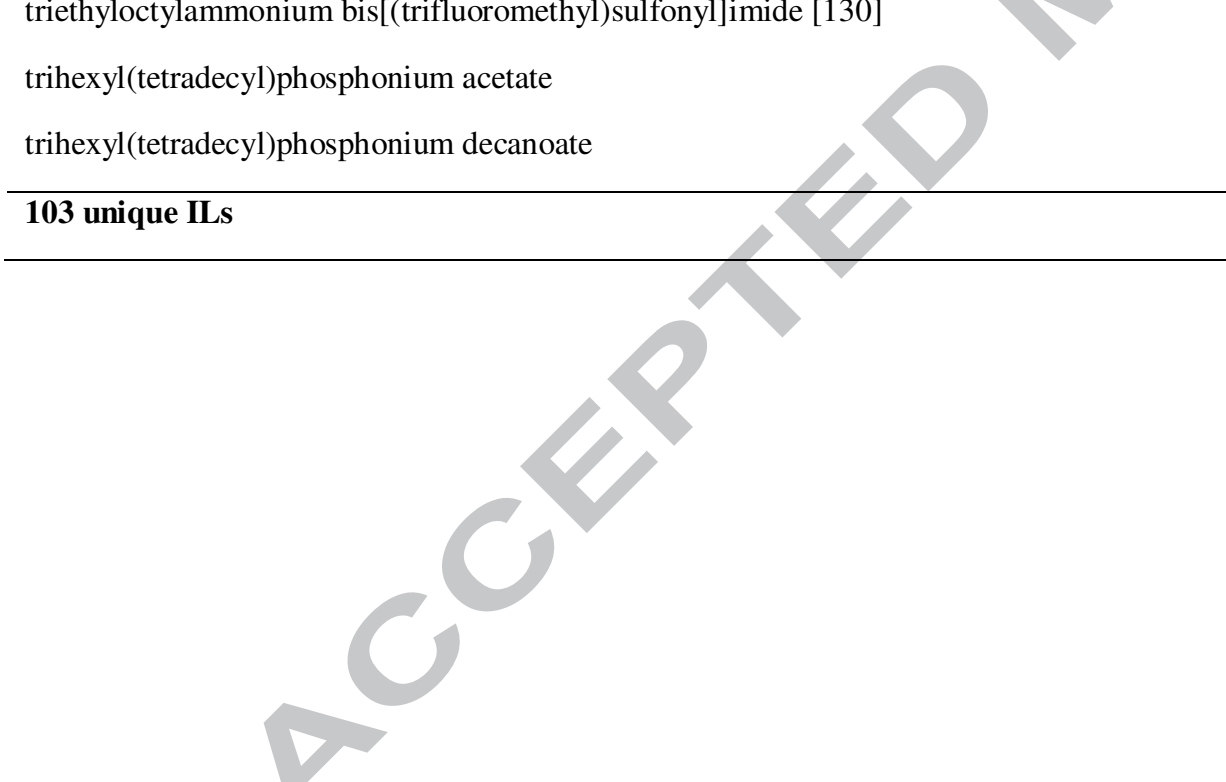
Table 6 Original and new parameters for equation (14) in the Ge-Nancarrow model for heat capacity.

\begin{tabular}{|c|c|c|c|c|c|}
\hline Group & $\begin{array}{l}A_{c p, i} \\
/ \mathbf{J} \mathbf{~ m o l}^{-1} \mathbf{K}^{-1}\end{array}$ & $\begin{array}{l}B_{c p, i} \cdot \mathbf{1 0}^{-3} \\
/ \mathbf{J} \mathbf{~ m o l}^{-1} \mathbf{K}^{-2}\end{array}$ & $\begin{array}{l}C_{c p, i} \cdot \mathbf{1 0}^{-5} \\
/ \mathrm{J} \mathbf{m o l}^{-1} \mathrm{~K}^{-3}\end{array}$ & 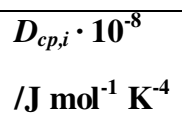 & Amount of data points \\
\hline \multicolumn{6}{|l|}{ Without rings } \\
\hline$-\mathrm{CH}_{3, \text { neutral }}$ & 42.22 & -57.25 & 15.22 & -9.67 & 2676 \\
\hline$-\mathrm{CH}_{3, \mathrm{P}-\text { based }}$ & 16.25 & -74.10 & 15.24 & -9.67 & 50 \\
\hline$-\mathrm{CH}_{3, \mathrm{~N} \text {-based }}$ & 16.84 & 6.18 & 15.22 & -9.67 & 3217 \\
\hline$-\mathrm{CH}_{3, \text { anion-based }}$ & 11.51 & -29.01 & 15.40 & -9.67 & 583 \\
\hline$-\mathrm{CH}_{2}{ }^{-}$neutral & 1.62 & 92.40 & -5.54 & 1.19 & 1385 \\
\hline$-\mathrm{CH}_{2}-$ P-based & -6.86 & 58.95 & -5.47 & 1.19 & 08 \\
\hline$-\mathrm{CH}_{2}$-N-based & -9.15 & 111.90 & -5.28 & 1.19 & 3534 \\
\hline$-\mathrm{CH}_{2}$-anion-based & -28.24 & 163.54 & -5.41 & 1.19 & 622 \\
\hline$>\mathrm{CH}-$ & -23.00 & 204.00 & -26.50 & 12.00 & 124 \\
\hline$>\mathrm{C}<$ & -66.20 & 427.00 & -64.10 & 30.10 & 1638 \\
\hline$-\mathrm{OH}$ & 25.70 & -69.10 & 17.70 & -9.88 & 465 \\
\hline$-\mathrm{O}-$ & 25.50 & -63.20 & 11.10 & -5.48 & 794 \\
\hline$-\mathrm{COOH}$ & 24.10 & 42.70 & 8.04 & -6.87 & 58 \\
\hline$-\mathrm{COO}-$ & 24.50 & 40.2 & 4.02 & -4.52 & 665 \\
\hline$-\mathrm{NH}_{2}$ & 26.90 & -41.20 & 16.40 & -9.76 & 124 \\
\hline -NH- & -1.21 & 76.20 & -4.86 & 1.05 & 310 \\
\hline$>\mathrm{N}-{ }_{\text {cation-based }}$ & -132.83 & 419.70 & -32.03 & 14.60 & 639 \\
\hline & -9.42 & 143.76 & -31.84 & 14.60 & 1034 \\
\hline & 11.86 & 160.74 & -32.44 & 14.60 & 46 \\
\hline$-\mathrm{CN}$ & 36.50 & -73.30 & 18.40 & -10.30 & 275 \\
\hline$-F$ & 26.50 & -91.30 & 19.10 & -10.30 & 2053 \\
\hline$-\mathrm{Br}$ & 28.60 & -64.90 & 13.60 & -7.45 & 215 \\
\hline$-\mathrm{I}$ & 32.10 & -64.10 & 12.60 & -6.87 & 134 \\
\hline$-\mathrm{P}_{\text {cation-based }}$ & 22.58 & 596.68 & 0.52 & & 98 \\
\hline$-\mathrm{P}_{\text {anion-based }}$ & 51.30 & -253.86 & 0.01 & & 176 \\
\hline$-B$ & -71.24 & 211.46 & & & 481 \\
\hline -S- & -38.23 & 59.90 & & & 54 \\
\hline$-\mathrm{SO}_{2}$ & 90.18 & 7.53 & & & 1880 \\
\hline
\end{tabular}




\begin{tabular}{llllll}
\hline With rings & & & & \\
\hline$=\mathrm{CH}-$ & -2.14 & 57.40 & -0.16 & -1.59 & 2953 \\
$=\mathrm{C}<$ & -8.25 & 101.00 & -14.20 & 6.78 & 541 \\
$-\mathrm{O}-$ & 12.20 & -12.60 & 6.03 & -3.86 & 50 \\
$=\mathrm{N}-$ & 8.83 & -3.84 & 4.35 & -2.60 & 2953 \\
\hline
\end{tabular}

\section{Conclusions}

The prediction of thermophysical properties may lead to a significant reduction in the time and efficiency for designing heat transfer processes using ionic liquids as HTFs. However, robust models must be developed, in the meaning of accurate prediction in case of all type of ILs. Together with the development of these models, they should be checked with experimental data not included in the original model formulation. As presented, herein, very low deviations reported by the authors of models do not necessarily lead to good prediction for ionic liquids. This may be due to the range of interactions which are present in the ionic liquids. Unfortunately, it was found in this study that there is no reliable existing models for thermal conductivity and heat capacity which are able to predict these values with high accuracy or in good correlation to the experimental data for a range of tetraalkyl phosphonium carboxylate ionic liquids. Thus, the models for heat capacity and thermal conductivity were improved and the achieved results provide a better predictive capability for ILs. This model development included a novel approach to include the impact of cation core atom on the structure and physical properties of the ionic liquids and was included in the model with proper corrections.

\section{Acknowledgments}

The project was supported by King Faisal University (Saudi Arabia) through a research fund from the International Cooperation and Knowledge Exchange Administration department at KFU. 


\section{References}

[1] J.F. Brennecke, E.J. Maginn, Ionic liquids: innovative fluids for chemical processing, AIChE J. 47 (2001) 2384-2389.

[2] M.E. Van Valkenburg, R.L. Vaughn, M. Williams, J.S. Wilkes, Thermochemistry of ionic liquid heattransfer fluids, Thermochim. Acta. 425 (2005) 181-188.

[3] J.F. Wishart, Energy applications of ionic liquids, Energy Environ. Sci. 2 (2009) 956-961.

[4] Z. Lei, B. Chen, Y.-M. Koo, D.R. MacFarlane, Introduction: Ionic Liquids, Chem. Rev. 117 (2017) 6633-6635. doi:10.1021/acs.chemrev.7b00246.

[5] A. Noda, K. Hayamizu, M. Watanabe, Pulsed-gradient spin- echo 1H and 19F NMR ionic diffusion coefficient, viscosity, and ionic conductivity of non-chloroaluminate room-temperature ionic liquids, J. Phys. Chem. B. 105 (2001) 4603-4610.

[6] C. Schreiner, S. Zugmann, R. Hartl, H.J. Gores, Fractional Walden rule for ionic liquids: examples from recent measurements and a critique of the so-called ideal $\mathrm{KCl}$ line for the Walden plot, J. Chem. Eng. Data. 55 (2009) 1784-1788.

[7] T. Umecky, Y. Saito, H. Matsumoto, Direct Measurements of Ionic Mobility of Ionic Liquids Using the Electric Field Applying Pulsed Gradient Spin- Echo NMR, J. Phys. Chem. B. 113 (2009) 8466-8468.

[8] S. Aparicio, M. Atilhan, F. Karadas, Thermophysical properties of pure ionic liquids: review of present situation, Ind. Eng. Chem. Res. 49 (2010) 9580-9595.

[9] J.M.P. França, C.A. Nieto de Castro, M.M. Lopes, V.M.B. Nunes, Influence of thermophysical properties of ionic liquids in chemical process design, J. Chem. Eng. Data. 54 (2009) 2569-2575.

[10] S. Atashrouz, M. Mozaffarian, G. Pazuki, Modeling the Thermal Conductivity of Ionic Liquids and Ionanofluids Based on a Group Method of Data Handling and Modified Maxwell Model, Ind. Eng. Chem. Res. 54 (2015) 8600-8610.

[11] A.P. Fröba, M.H. Rausch, K. Krzeminski, D. Assenbaum, P. Wasserscheid, A. Leipertz, Thermal conductivity of ionic liquids: measurement and prediction, Int. J. Thermophys. 31 (2010) 2059-2077.

[12] R.L. Gardas, J.A.P. Coutinho, A group contribution method for heat capacity estimation of ionic liquids, Ind. Eng. Chem. Res. 47 (2008) 5751-5757.

[13] R.L. Gardas, J.A.P. Coutinho, Group contribution methods for the prediction of thermophysical and transport properties of ionic liquids, AIChE J. 55 (2009) 1274-1290.

[14] R. Ge, C. Hardacre, J. Jacquemin, P. Nancarrow, D.W. Rooney, Heat capacities of ionic liquids as a function of temperature at 0.1 MPa. Measurement and prediction, J. Chem. Eng. Data. 53 (2008) 21482153.

[15] A.Z. Hezave, S. Raeissi, M. Lashkarbolooki, Estimation of thermal conductivity of ionic liquids using a perceptron neural network, Ind. Eng. Chem. Res. 51 (2012) 9886-9893.

[16] J.A. Lazzús, A group contribution method to predict the thermal conductivity $\lambda$ (T, P) of ionic liquids, Fluid Phase Equilib. 405 (2015) 141-149.

[17] P. Nancarrow, M. Lewis, L. AbouChacra, Group contribution methods for estimation of ionic liquid heat capacities: critical evaluation and extension, Chem. Eng. Technol. 38 (2015) 632-644.

[18] S.A. Shojaee, S. Farzam, A.Z. Hezave, M. Lashkarbolooki, S. Ayatollahi, A new correlation for estimating thermal conductivity of pure ionic liquids, Fluid Phase Equilib. 354 (2013) 199-206.

[19] A.N. Soriano, A.M. Agapito, L.J.L.I. Lagumbay, A.R. Caparanga, M.-H. Li, A simple approach to predict molar heat capacity of ionic liquids using group-additivity method, J. Taiwan Inst. Chem. Eng. 41 (2010) 307-314. 
[20] D. Tomida, S. Kenmochi, T. Tsukada, K. Qiao, C. Yokoyama, Thermal conductivities of [bmim][PF6],[hmim][PF6], and [omim][PF6] from 294 to $335 \mathrm{~K}$ at pressures up to $20 \mathrm{MPa}$, Int. J. Thermophys. 28 (2007) 1147-1160.

[21] J.O. Valderrama, L.A. Forero, R.E. Rojas, Critical properties and normal boiling temperature of ionic liquids. Update and a new consistency test, Ind. Eng. Chem. Res. 51 (2012) 7838-7844.

[22] J.O. Valderrama, L.A. Forero, R.E. Rojas, Extension of a group contribution method to estimate the critical properties of ionic liquids of high molecular mass, Ind. Eng. Chem. Res. 54 (2015) 3480-3487.

[23] J.O. Valderrama, G. Martinez, R.E. Rojas, Predictive model for the heat capacity of ionic liquids using the mass connectivity index, Thermochim. Acta. 513 (2011) 83-87.

[24] J.O. Valderrama, A. Toro, R.E. Rojas, Prediction of the heat capacity of ionic liquids using the mass connectivity index and a group contribution method, J. Chem. Thermodyn. 43 (2011) 1068-1073.

[25] K.-J. Wu, C.-X. Zhao, C.-H. He, Development of a group contribution method for determination of thermal conductivity of ionic liquids, Fluid Phase Equilib. 339 (2013) 10-14.

[26] J. Gmehling, D. Constantinescu, B. Schmid, Group contribution methods for phase equilibrium calculations, Annu. Rev. Chem. Biomol. Eng. 6 (2015) 267-292.

[27] M.D. Jankowski, C.S. Henry, L.J. Broadbelt, V. Hatzimanikatis, Group contribution method for thermodynamic analysis of complex metabolic networks, Biophys. J. 95 (2008) 1487-1499.

[28] S.S. Mansouri, A. Farsi, V. Shadravan, S. Ghader, Density calculation of liquid organic compounds using a simple equation of state up to high pressures, J. Mol. Liq. 160 (2011) 94-102.

[29] J. Marrero, R. Gani, Group-contribution based estimation of pure component properties, Fluid Phase Equilib. 183 (2001) 183-208.

[30] M. Moosavi, Extension of GMA equation of state to long-chain alkanes using group contribution method, Ind. Eng. Chem. Res. 49 (2010) 6662-6669.

[31] E. Zorębski, M. Zorębski, M. Dzida, P. Goodrich, J. Jacquemin, Isobaric and Isochoric Heat Capacities of Imidazolium-Based and Pyrrolidinium-Based Ionic Liquids as a Function of Temperature: Modeling of Isobaric Heat Capacity, Ind. Eng. Chem. Res. 56 (2017) 2592-2606.

[32] M. Dzida, E. Zorębski, M. Zorębski, M. Żarska, M. Geppert-Rybczyńska, M. Chorążewski, J. Jacquemin, I. Cibulka, Speed of Sound and Ultrasound Absorption in Ionic Liquids, Chem. Rev. 117 (2017) 3883-3929.

[33] Y. Zhao, S. Zeng, Y. Huang, R.M. Afzal, X. Zhang, Estimation of Heat Capacity of Ionic Liquids Using S $\sigma$-profile Molecular Descriptors, Ind. Eng. Chem. Res. 54 (2015) 12987-12992.

[34] L.P.N. Rebelo, J.N. Canongia Lopes, J.M.S.S. Esperança, E. Filipe, On the critical temperature, normal boiling point, and vapor pressure of ionic liquids, J. Phys. Chem. B. 109 (2005) 6040-6043.

[35] J.O. Valderrama, P.A. Robles, Critical properties, normal boiling temperatures, and acentric factors of fifty ionic liquids, Ind. Eng. Chem. Res. 46 (2007) 1338-1344.

[36] G. Gurau, H. Rodríguez, S.P. Kelley, P. Janiczek, R.S. Kalb, R.D. Rogers, Demonstration of Chemisorption of Carbon Dioxide in 1, 3-Dialkylimidazolium Acetate Ionic Liquids, Angew. Chemie Int. Ed. 50 (2011) 12024-12026.

[37] K. Ninomiya, T. Yamauchi, M. Kobayashi, C. Ogino, N. Shimizu, K. Takahashi, Cholinium carboxylate ionic liquids for pretreatment of lignocellulosic materials to enhance subsequent enzymatic saccharification, Biochem. Eng. J. 71 (2013) 25-29.

[38] A. Xu, J. Wang, Y. Zhang, Q. Chen, Effect of alkyl chain length in anions on thermodynamic and surface properties of 1-butyl-3-methylimidazolium carboxylate ionic liquids, Ind. Eng. Chem. Res. 51 (2012) 3458-3465.

[39] M. Diedenhofen, A. Klamt, K. Marsh, A. Schäfer, Prediction of the vapor pressure and vaporization enthalpy of 1-n-alkyl-3-methylimidazolium-bis-(trifluoromethanesulfonyl) amide ionic liquids, Phys. Chem. Chem. Phys. 9 (2007) 4653-4656. 
[40] C. Wang, H. Luo, D. Jiang, H. Li, S. Dai, Carbon Dioxide Capture by Superbase-Derived Protic Ionic Liquids, Angew. Chemie Int. Ed. 49 (2010) 5978-5981.

[41] S. Zahn, D.R. MacFarlane, E.I. Izgorodina, Assessment of Kohn-Sham density functional theory and Møller-Plesset perturbation theory for ionic liquids, Phys. Chem. Chem. Phys. 15 (2013) 13664-13675.

[42] P.A. Hunt, B. Kirchner, T. Welton, Characterising the Electronic Structure of Ionic Liquids: An Examination of the 1-Butyl-3-Methylimidazolium Chloride Ion Pair, Chem. Eur. J. 12 (2006) 67626775.

[43] S.M. Urahata, M.C.C. Ribeiro, Structure of ionic liquids of 1-alkyl-3-methylimidazolium cations: A systematic computer simulation study, J. Chem. Phys. 120 (2004) 1855-1863.

[44] A. Fredenslund, R.L. Jones, J.M. Prausnitz, Group-contribution estimation of activity coefficients in nonideal liquid mixtures, AIChE J. 21 (1975) 1086-1099.

[45] K.G. Joback, R.C. Reid, Estimation of pure-component properties from group-contributions, Chem. Eng. Commun. 57 (1987) 233-243.

[46] R. Kühne, R.-U. Ebert, F. Kleint, G. Schmidt, G. Schüürmann, Group contribution methods to estimate water solubility of organic chemicals, Chemosphere. 30 (1995) 2061-2077.

[47] D.T. Wu, Prediction of viscosities of liquid mixtures by a group contribution method, Fluid Phase Equilib. 30 (1986) 149-156.

[48] P.A. Hunt, C.R. Ashworth, R.P. Matthews, Hydrogen bonding in ionic liquids, Chem. Soc. Rev. 44 (2015) 1257-1288.

[49] R.P. Matthews, T. Welton, P.A. Hunt, Competitive pi interactions and hydrogen bonding within imidazolium ionic liquids, Phys. Chem. Chem. Phys. 16 (2014) 3238-3253.

[50] S.W. Benson, J.H. Buss, Additivity rules for the estimation of molecular properties. Thermodynamic properties, J. Chem. Phys. 29 (1958) 546-572.

[51] K.G. Joback, A unified approach to physical property estimation using multivariate statistical techniques, Massachusetts Institute of Technology, 1984.

[52] R. Ge, C. Hardacre, P. Nancarrow, D.W. Rooney, Thermal conductivities of ionic liquids over the temperature range from 293 K to 353 K, J. Chem. Eng. Data. 52 (2007) 1819-1823.

[53] M.J. Assael, E. Charitidou, W.A. Wakeham, Absolute measurements of the thermal conductivity of mixtures of alcohols with water, Int. J. Thermophys. 10 (1989) 793-803.

[54] C.A. Nieto de Castro, M.J. V Lourenço, A.P.C. Ribeiro, E. Langa, S.I.C. Vieira, P. Goodrich, C. Hardacre, Thermal properties of ionic liquids and ionanofluids of imidazolium and pyrrolidinium liquids, J. Chem. Eng. Data. 55 (2009) 653-661.

[55] L. Constantinou, R. Gani, New group contribution method for estimating properties of pure compounds, AIChE J. 40 (1994) 1697-1710.

[56] H.S. Elbro, A. Fredenslund, P. Rasmussen, Group contribution method for the prediction of liquid densities as a function of temperature for solvents, oligomers, and polymers, Ind. Eng. Chem. Res. 30 (1991) 2576-2582.

[57] D. Tomida, S. Kenmochi, T. Tsukada, C. Yokoyama, Measurements of thermal conductivity of 1-butyl-3-methylimidazolium tetrafluoroborate at high pressure, Heat Transf. Res. 36 (2007) 361-372.

[58] J.M.P. França, S.I.C. Vieira, M.J. V Lourenço, S.M.S. Murshed, C.A. Nieto de Castro, Thermal Conductivity of [C4mim] [(CF3SO2) $2 \mathrm{~N}]$ and [C2mim][EtSO4] and Their IoNanofluids with Carbon Nanotubes: Experiment and Theory, J. Chem. Eng. Data. 58 (2013) 467-476.

[59] T.M. Koller, S.R. Schmid, S.J. Sachnov, M.H. Rausch, P. Wasserscheid, A.P. Fröba, Measurement and Prediction of the Thermal Conductivity of Tricyanomethanide-and Tetracyanoborate-Based Imidazolium Ionic Liquids, Int. J. Thermophys. 35 (2014) 195-217.

[60] D. Tomida, S. Kenmochi, K. Qiao, T. Tsukada, C. Yokoyama, Densities and thermal conductivities of 
N-alkylpyridinium tetrafluoroborates at high pressure, Fluid Phase Equilib. 340 (2013) 31-36.

[61] D. Tomida, S. Kenmochi, T. Tsukada, K. Qiao, Q. Bao, C. Yokoyama, Viscosity and thermal conductivity of 1-hexyl-3-methylimidazolium tetrafluoroborate and 1-octyl-3-methylimidazolium tetrafluoroborate at pressures up to $20 \mathrm{MPa}$, Int. J. Thermophys. 33 (2012) 959-969.

[62] H. Liu, E. Maginn, A.E. Visser, N.J. Bridges, E.B. Fox, Thermal and transport properties of six ionic liquids: an experimental and molecular dynamics study, Ind. Eng. Chem. Res. 51 (2012) 7242-7254.

[63] R.L. Gardas, R. Ge, P. Goodrich, C. Hardacre, A. Hussain, D.W. Rooney, Thermophysical properties of amino acid-based ionic liquids, J. Chem. Eng. Data. 55 (2009) 1505-1515.

[64] A.G.M. Ferreira, P.N. Simões, A.F. Ferreira, M.A. Fonseca, M.S.A. Oliveira, A.S.M. Trino, Transport and thermal properties of quaternary phosphonium ionic liquids and IoNanofluids, J. Chem. Thermodyn. 64 (2013) 80-92.

[65] N. Calvar, E. Gómez, E.A. Macedo, Á. Domínguez, Thermal analysis and heat capacities of pyridinium and imidazolium ionic liquids, Thermochim. Acta. 565 (2013) 178-182.

[66] G. Chatel, L. Leclerc, E. Naffrechoux, C. Bas, N. Kardos, C. Goux-Henry, B. Andrioletti, M. Draye, Ultrasonic properties of hydrophobic bis (trifluoromethylsulfonyl) imide-based ionic liquids, J. Chem. Eng. Data. 57 (2012) 3385-3390.

[67] A.F. Ferreira, P.N. Simões, A.G.M. Ferreira, Quaternary phosphonium-based ionic liquids: Thermal stability and heat capacity of the liquid phase, J. Chem. Thermodyn. 45 (2012) 16-27.

[68] U. Domańska, R. Bogel-Łukasik, Physicochemical properties and solubility of alkyl-(2-hydroxyethyl)dimethylammonium bromide, J. Phys. Chem. B. 109 (2005) 12124-12132.

[69] G. García-Miaja, J. Troncoso, L. Romaní, Excess enthalpy, density, and heat capacity for binary systems of alkylimidazolium-based ionic liquids+ water, J. Chem. Thermodyn. 41 (2009) 161-166.

[70] Y.A. Sanmamed, P. Navia, D. González-Salgado, J. Troncoso, L. Romaní, Pressure and temperature dependence of isobaric heat capacity for [Emim][BF4],[Bmim][BF4],[Hmim][BF4], and [Omim][BF4], J. Chem. Eng. Data. 55 (2009) 600-604.

[71] G.J. Kabo, A. V Blokhin, Y.U. Paulechka, A.G. Kabo, M.P. Shymanovich, J.W. Magee, Thermodynamic properties of 1-butyl-3-methylimidazolium hexafluorophosphate in the condensed state, J. Chem. Eng. Data. 49 (2004) 453-461.

[72] P. Navarro, M. Larriba, J. García, F. Rodríguez, Thermal stability and specific heats of $\{[\mathrm{emim}][\mathrm{DCA}]+[\mathrm{emim}][\mathrm{TCM}]\}$ mixed ionic liquids, Thermochim. Acta. 588 (2014) 22-27.

[73] D. Waliszewski, I. Stępniak, H. Piekarski, A. Lewandowski, Heat capacities of ionic liquids and their heats of solution in molecular liquids, Thermochim. Acta. 433 (2005) 149-152.

[74] U. Domańska, M. Zawadzki, M. Zwolińska, Thermophysical properties and phase equilibria study of the binary systems $\{\mathrm{N}$-hexylquinolinium bis (trifluoromethylsulfonyl) imide+ aromatic hydrocarbons, or an alcohol \}, J. Chem. Thermodyn. 43 (2011) 775-781.

[75] N.M.C. Talavera-Prieto, A.G.M. Ferreira, P.N. Simões, P.J. Carvalho, S. Mattedi, J.A.P. Coutinho, Thermophysical characterization of N-methyl-2-hydroxyethylammonium carboxilate ionic liquids, J. Chem. Thermodyn. 68 (2014) 221-234.

[76] L.E. Ficke, H. Rodríguez, J.F. Brennecke, Heat capacities and excess enthalpies of 1-ethyl-3methylimidazolium-based ionic liquids and water, J. Chem. Eng. Data. 53 (2008) 2112-2119.

[77] S. Aparicio, R. Alcalde, B. Garcia, J.M. Leal, High-pressure study of the methylsulfate and tosylate imidazolium ionic liquids, J. Phys. Chem. B. 113 (2009) 5593-5606.

[78] Y.U. Paulechka, A.G. Kabo, A. V Blokhin, G.J. Kabo, M.P. Shevelyova, Heat capacity of ionic liquids: experimental determination and correlations with molar volume, J. Chem. Eng. Data. 55 (2010) 27192724.

[79] E.J. González, Á. Domínguez, E.A. Macedo, Physical and excess properties of eight binary mixtures containing water and ionic liquids, J. Chem. Eng. Data. 57 (2012) 2165-2176. 
[80] C.P. Fredlake, J.M. Crosthwaite, D.G. Hert, S.N.V.K. Aki, J.F. Brennecke, Thermophysical properties of imidazolium-based ionic liquids, J. Chem. Eng. Data. 49 (2004) 954-964.

[81] H.-C. Hu, A.N. Soriano, R.B. Leron, M.-H. Li, Molar heat capacity of four aqueous ionic liquid mixtures, Thermochim. Acta. 519 (2011) 44-49.

[82] I. Bandres, G. Pera, S. Martin, M. Castro, C. Lafuente, Thermophysical study of 1-butyl-2methylpyridinium tetrafluoroborate ionic liquid, J. Phys. Chem. B. 113 (2009) 11936-11942.

[83] U. Domańska, K. Skiba, M. Zawadzki, K. Paduszyński, M. Królikowski, Synthesis, physical, and thermodynamic properties of 1-alkyl-cyanopyridinium bis $\{$ (trifluoromethyl) sulfonyl $\}$ imide ionic liquids, J. Chem. Thermodyn. 56 (2013) 153-161.

[84] J. Safarov, M. Geppert-Rybczyńska, I. Kul, E. Hassel, Thermophysical properties of 1-butyl-3methylimidazolium acetate over a wide range of temperatures and pressures, Fluid Phase Equilib. 383 (2014) 144-155.

[85] A.A. Strechan, Y.U. Paulechka, A. V Blokhin, G.J. Kabo, Low-temperature heat capacity of hydrophilic ionic liquids [BMIM][CF $3 \mathrm{COO}]$ and [BMIM] [CH $3 \mathrm{COO}]$ and a correlation scheme for estimation of heat capacity of ionic liquids, J. Chem. Thermodyn. 40 (2008) 632-639.

[86] M. Yang, J.-N. Zhao, Q.-S. Liu, L.-X. Sun, P.-F. Yan, Z.-C. Tan, U. Welz-Biermann, Low-temperature heat capacities of 1-alkyl-3-methylimidazolium bis (oxalato) borate ionic liquids and the influence of anion structural characteristics on thermodynamic properties, Phys. Chem. Chem. Phys. 13 (2011) 199206.

[87] A. V Blokhin, Y.U. Paulechka, A.A. Strechan, G.J. Kabo, Physicochemical properties, structure, and conformations of 1-butyl-3-methylimidazolium bis (trifluoromethanesulfonyl) imide [C4mim] NTf2 ionic liquid, J. Phys. Chem. B. 112 (2008) 4357-4364.

[88] J. Troncoso, C.A. Cerdeiriña, Y.A. Sanmamed, L. Romaní, L.P.N. Rebelo, Thermodynamic properties of imidazolium-based ionic liquids: densities, heat capacities, and enthalpies of fusion of [bmim][PF6] and [bmim][NTf2], J. Chem. Eng. Data. 51 (2006) 1856-1859.

[89] K.S. Kim, H. Lee, Separation Technology, Thermodynamics: Physical and Electrochemical Properties of 1-Butyl-3-methylimidazolium Bromide, 1-Butyl-3-methylimidazolium Iodide, and 1-Butyl-3methylimidazolium Tetrafluoroborate, Korean J. Chem. Eng. 21 (2004) 1010-1014.

[90] K.-S. Kim, B.-K. Shin, H. Lee, F. Ziegler, Refractive index and heat capacity of 1-butyl-3methylimidazolium bromide and 1-butyl-3-methylimidazolium tetrafluoroborate, and vapor pressure of binary systems for 1-butyl-3-methylimidazolium bromide+ trifluoroethanol and 1-butyl-3methylimidazolium tet, Fluid Phase Equilib. 218 (2004) 215-220.

[91] Y.U. Paulechka, G.J. Kabo, A. V Blokhin, A.S. Shaplov, E.I. Lozinskaya, Y.S. Vygodskii, Thermodynamic properties of 1-alkyl-3-methylimidazolium bromide ionic liquids, J. Chem. Thermodyn. 39 (2007) 158-166.

[92] C.A.N. de Castro, E. Langa, A.L. Morais, M.L.M. Lopes, M.J. V Lourenço, F.J. V Santos, M.S.C.S. Santos, J.N.C. Lopes, H.I.M. Veiga, M. Macatrão, Studies on the density, heat capacity, surface tension and infinite dilution diffusion with the ionic liquids [C $4 \mathrm{mim}$ ][NTf 2],[C $4 \mathrm{mim}$ ][dca],[C 2 mim][EtOSO 3] and [Aliquat][dca], Fluid Phase Equilib. 294 (2010) 157-179.

[93] P. Navarro, M. Larriba, E. Rojo, J. García, F. Rodríguez, Thermal properties of cyano-based ionic liquids, J. Chem. Eng. Data. 58 (2013) 2187-2193.

[94] G.J. Kabo, Y.U. Paulechka, A.G. Kabo, A. V Blokhin, Experimental determination of enthalpy of 1butyl-3-methylimidazolium iodide synthesis and prediction of enthalpies of formation for imidazolium ionic liquids, J. Chem. Thermodyn. 42 (2010) 1292-1297.

[95] Y.U. Paulechka, A. V Blokhin, Low-temperature heat capacity and derived thermodynamic properties for 1-methyl-3-propylimidazolium bromide and 1-butyl-3-methylimidazolium iodide, J. Chem. Thermodyn. 79 (2014) 94-99.

[96] G. García-Miaja, J. Troncoso, L. Romaní, Excess properties for binary systems ionic liquid+ ethanol: Experimental results and theoretical description using the ERAS model, Fluid Phase Equilib. 274 (2008) 
59-67.

[97] G. García-Miaja, J. Troncoso, L. Romaní, Excess molar properties for binary systems of alkylimidazolium-based ionic liquids+ nitromethane. Experimental results and ERAS-model calculations, J. Chem. Thermodyn. 41 (2009) 334-341.

[98] M.J. Dávila, S. Aparicio, R. Alcalde, B. García, J.M. Leal, On the properties of 1-butyl-3methylimidazolium octylsulfate ionic liquid, Green Chem. 9 (2007) 221-232.

[99] S.N. Shah, K.C. Lethesh, M.I.A. Mutalib, R.B.M. Pilus, Evaluation of thermophysical properties of imidazolium-based phenolate ionic liquids, Ind. Eng. Chem. Res. 54 (2015) 3697-3705.

[100] L.P.N. Rebelo, V. Najdanovic-Visak, Z.P. Visak, M.N. Da Ponte, J. Szydlowski, C.A. Cerdeirina, J. Troncoso, L. Romani, J. Esperanca, H.J.R. Guedes, A detailed thermodynamic analysis of [C 4 mim][BF 4]+ water as a case study to model ionic liquid aqueous solutions, Green Chem. 6 (2004) 369381.

[101] A. Diedrichs, J. Gmehling, Measurement of heat capacities of ionic liquids by differential scanning calorimetry, Fluid Phase Equilib. 244 (2006) 68-77.

[102] J.M. Crosthwaite, M.J. Muldoon, J.K. Dixon, J.L. Anderson, J.F. Brennecke, Phase transition and decomposition temperatures, heat capacities and viscosities of pyridinium ionic liquids, J. Chem. Thermodyn. 37 (2005) 559-568.

[103] Z. Zhang, L. Sun, Z. Tan, F. Xu, X. Lv, J. Zeng, Y. Sawada, Thermodynamic investigation of room temperature ionic liquid: heat capacity and thermodynamic functions of BPBF4, J. Therm. Anal. Calorim. 89 (2006) 289-294.

[104] M.G. Freire, A.R.R. Teles, M.A.A. Rocha, B. Schröder, C.M.S.S. Neves, P.J. Carvalho, D. V Evtuguin, L.M. Santos, J.A.P. Coutinho, Thermophysical characterization of ionic liquids able to dissolve biomass, J. Chem. Eng. Data. 56 (2011) 4813-4822.

[105] M. Dzida, M. Chorążewski, M. Geppert-Rybczyńska, E. Zorębski, M. Zorębski, M. Żarska, B. Czech, Speed of sound and adiabatic compressibility of 1-ethyl-3-methylimidazolium bis (trifluoromethylsulfonyl) imide under pressures up to $100 \mathrm{MPa}$, J. Chem. Eng. Data. 58 (2013) 15711576.

[106] Y.-H. Yu, A.N. Soriano, M.-H. Li, Heat capacities and electrical conductivities of 1-ethyl-3methylimidazolium-based ionic liquids, J. Chem. Thermodyn. 41 (2009) 103-108.

[107] Y.U. Paulechka, A. V Blokhin, G.J. Kabo, Evaluation of thermodynamic properties for noncrystallizable ionic liquids, Thermochim. Acta. 604 (2015) 122-128.

[108] P.F. Requejo, E.J. González, E.A. Macedo, Á. Domínguez, Effect of the temperature on the physical properties of the pure ionic liquid 1-ethyl-3-methylimidazolium methylsulfate and characterization of its binary mixtures with alcohols, J. Chem. Thermodyn. 74 (2014) 193-200.

[109] V.K. Sharma, S. Bhagour, S. Solanki, D. Sharma, Excess heat capacities of (binary+ ternary) mixtures containing [emim][BF 4] and organic liquids, J. Chem. Thermodyn. 79 (2014) 19-32.

[110] V.K. Sharma, S. Solanki, S. Bhagour, Thermodynamic properties of ternary mixtures containing ionic liquid and organic liquids: excess molar volume and excess isentropic compressibility, J. Chem. Eng. Data. 59 (2014) 1140-1157.

[111] V.K. Sharma, S. Solanki, S. Bhagour, Excess heat capacities of binary and ternary mixtures containing 1-ethyl-3-methylimidazolium tetrafluoroborate and anilines, J. Chem. Eng. Data. 59 (2014) 1852-1864.

[112] J. Benito, M. García-Mardones, V. Pérez-Gregorio, I. Gascón, C. Lafuente, Physicochemical study of nethylpyridinium bis (trifluoromethylsulfonyl) imide ionic liquid, J. Solution Chem. 43 (2014) 696-710.

[113] B. Tong, Q.-S. Liu, Z.-C. Tan, U. Welz-Biermann, Thermochemistry of alkyl pyridinium bromide ionic liquids: calorimetric measurements and calculations, J. Phys. Chem. A. 114 (2009) 3782-3787.

[114] M.A.A. Rocha, M. Bastos, J.A.P. Coutinho, L.M. Santos, Heat capacities at 298.15 K of the extended [CnC $1 \mathrm{im}][\mathrm{Ntf} 2]$ ionic liquid series, J. Chem. Thermodyn. 53 (2012) 140-143. 
[115] D.G. Archer, Thermodynamic Properties of 1-hexyl-3-methylimidazolium Bis (trifluoromethylsulfony) imide, US Department of Commerce, Technology Administration, National Institute of Standards and Technology, 2006.

[116] A. V Blokhin, Y.U. Paulechka, G.J. Kabo, Thermodynamic properties of [C6mim][NTf2] in the condensed state, J. Chem. Eng. Data. 51 (2006) 1377-1388.

[117] J.-G. Li, Y.-F. Hu, S. Ling, J.-Z. Zhang, Physicochemical properties of [C6mim][PF6] and [C6mim][(C2F5) 3PF3] ionic liquids, J. Chem. Eng. Data. 56 (2011) 3068-3072.

[118] D. Waliszewski, Heat capacities of the mixtures of ionic liquids with methanol at temperatures from 283.15 K to 323.15 K, J. Chem. Thermodyn. 40 (2008) 203-207.

[119] G.W. Meindersma, B.T.J. Simons, A.B. De Haan, Physical properties of 3-methyl-N-butylpyridinium tetracyanoborate and 1-butyl-1-methylpyrrolidinium tetracyanoborate and ternary LLE data of [3mebupy] $\mathrm{B}(\mathrm{CN}) 4$ with an aromatic and an aliphatic hydrocarbon at $\mathrm{T}=303.2 \mathrm{~K}$ and $328.2 \mathrm{~K}$ and $\mathrm{p}=0.1$ MPa, J. Chem. Thermodyn. 43 (2011) 1628-1640.

[120] C.J. Rao, R.V. Krishnan, K.A. Venkatesan, K. Nagarajan, T.G. Srinivasan, Thermochemical properties of some bis (trifluoromethyl-sulfonyl) imide based room temperature ionic liquids, J. Therm. Anal. Calorim. 97 (2009) 937.

[121] D. Waliszewski, H. Piekarski, Heat capacities of the mixtures of ionic liquids with acetonitrile, J. Chem. Thermodyn. 42 (2010) 189-192.

[122] E. Gómez, N. Calvar, Á. Domínguez, E. A. Macedo, Thermal Analysis and Heat Capacities of 1-Alkyl3-methylimidazolium Ionic Liquids with NTf2-, TFO-, and DCA-Anions, Ind. Eng. Chem. Res. 52 (2013) 2103-2110.

[123] Q.-S. Liu, Z.-C. Tan, U. Welz-Biermann, X.-X. Liu, Molar heat capacity and thermodynamic properties of N-alklypyridinium hexafluorophosphate salts, $[\mathrm{Cnpy}][\mathrm{PF} 6](\mathrm{n}=2,3,5)$, J. Chem. Thermodyn. 68 (2014) 82-89.

[124] I. Bandrés, M.C. López, M. Castro, J. Barberá, C. Lafuente, Thermophysical properties of 1 propylpyridinium tetrafluoroborate, J. Chem. Thermodyn. 44 (2012) 148-153.

[125] M. Mahrova, M. Vilas, A. Dominguez, E. Gómez, N. Calvar, E. Tojo, Physicochemical characterization of new sulfonate and sulfate ammonium ionic liquids, J. Chem. Eng. Data. 57 (2012) 241-248.

[126] M. García-Mardones, I. Bandrés, M.C. López, I. Gascón, C. Lafuente, Experimental and theoretical study of two pyridinium-based ionic liquids, J. Solution Chem. 41 (2012) 1836-1852.

[127] M. Królikowska, K. Paduszyński, M. Zawadzki, Measurements, correlations, and predictions of thermodynamic properties of N-octylisoquinolinium thiocyanate ionic liquid and its aqueous solutions, J. Chem. Eng. Data. 58 (2013) 285-293.

[128] Q.-S. Liu, J.-N. Zhao, J. Tong, L.-X. Sun, Z.-C. Tan, U. Welz-Biermann, Thermodynamic Properties of 1-Propyl-3-methylimidazolium Glutamic Acid Salt, J. Chem. Eng. Data. 55 (2010) 4036-4038.

[129] X.-H. Sun, Y.-F. Liu, Z.-C. Tan, Y.-Y. Di, H.-F. Wang, M.-H. Wang, Heat capacity and enthalpy of fusion of pyrimethanil laurate (C 24 H 37 N 3 O 2), J. Chem. Thermodyn. 36 (2004) 895-899.

[130] K. Machanová, Z. Wagner, A. Andresová, J. Rotrekl, A. Boisset, J. Jacquemin, M. Bendová, Thermal Properties of Alkyl-triethylammonium bis $\backslash\{$ (trifluoromethyl) sulfonyl $\}$ imide Ionic Liquids, J. Solution Chem. 44 (2015) 790-810. 
Further Development of the Predictive Models for Physical Properties of Pure Ionic Liquids: Thermal Conductivity and Heat Capacity

K. Oster ${ }^{1,2^{*}}$, J. Jacquemin $^{2,3}$, C. Hardacre ${ }^{1,2^{*}}$, A. P. C. Ribeiro ${ }^{4}$, A. Elsinawi $^{5}$

${ }^{1}$ The University of Manchester, School of Chemical Engineering \& Analytical Science, Sackville Street, M13 9PL, Manchester

${ }^{2}$ Queen's University Belfast, School of Chemistry \& Chemical Engineering, Stranmillis Road, BT9 5BW, Belfast

${ }^{3}$ Université François Rabelais, Laboratoire PCM2E, Parc de Grandmont 37200 Tours

${ }^{4}$ Universidade de Lisboa, Centro de Química Estrutural, Instituto Superior Técnico, Av. Rovisco Pais 1, 1049-001, Lisboa

${ }^{5}$ King Fasial University, Materials Engineering Department, College of Engineering, AlHasa, 31982, Hofuf

\section{Highlights}

- The thermal conductivity and heat capacity prediction of pure ionic liquids was performed and revised;

- The models for thermal conductivity and heat capacity prediction were improved;

- The density functional theory was used to investigate the Mulliken charge distribution to include it in the prediction of heat capacity. 